Staff Working Paper/Document de travail du personnel 2021-18

Last updated: April 7, 2021

\title{
Examining the Impact of Home Purchase Restrictions on China's Housing Market
}

by Zhentong Lu, ${ }^{1}$ Sisi Zhang ${ }^{2}$ and Jian Hong $^{3}$

${ }^{1}$ Financial Stability Department,

Bank of Canada, Ottawa, Ontario, Canada K1A 0G9

${ }^{2}$ Institute for Economic and Social Research

Jinan University, Guangzhou, 510632, China

${ }^{3}$ School of Economics

Shanghai University of Finance and Economics

zlu@bankofcanada.ca, sisi.zhang@gmail.com, hongjian1206@163.com

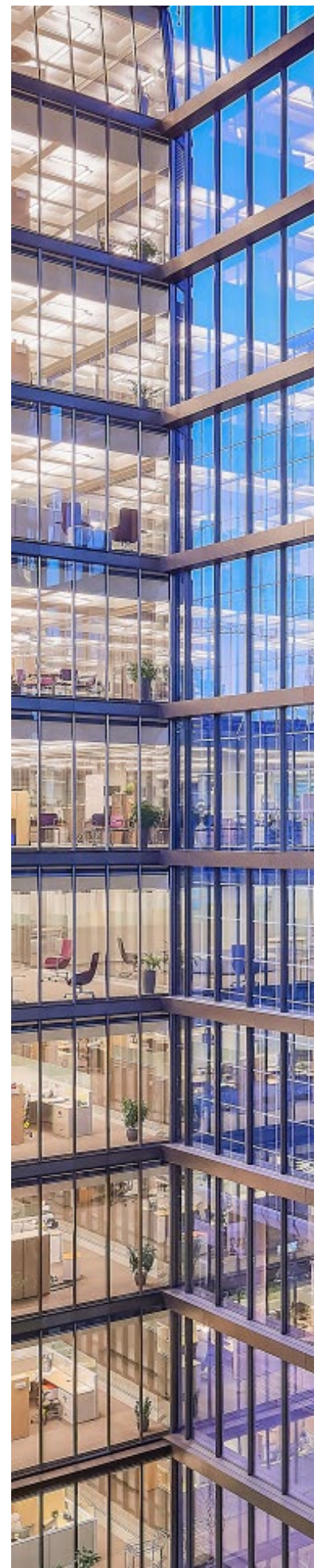

Bank of Canada staff working papers provide a forum for staff to publish work-in-progress research independently from the Bank's Governing Council. This research may support or challenge prevailing policy orthodoxy. Therefore, the views expressed in this paper are solely those of the authors and may differ from official Bank of Canada views. No responsibility for them should be attributed to the Bank. 


\section{Acknowledgements}

We would like to thank the participants at the 2019 Econometric Society China Meeting, 2017

Singapore Management University Conference on Urban and Regional Economics as well as seminar participants at Bank of Canada, Brock University for their many helpful comments and questions. 


\section{Abstract}

This paper studies the impact of home purchase restrictions on China's housing market. We estimate a structural model of household preference for housing, real estate developers'

pricing decisions, and equilibrium market outcome in five large cities. By comparing the estimation results from pre- and post-policy intervention, we find that after home purchase restrictions are implemented, overall housing demand in most cities becomes weaker and less price elastic; meanwhile, real estate developers face higher holding costs and thus are willing to lower prices and sell more quickly. Counterfactual analyses show that in some cities, alternative policy designs that cause less structural change of demand could improve consumer welfare and social welfare better than the implemented policy.

Topics: Housing; Market structure and pricing

JEL codes: R3 1; R38; 018 


\section{Introduction}

Housing is a basic need as well as an important asset for many families, and the real estate market plays an integral role in an economy. Market failure problems are prominent in housing markets, and many governments impose various regulations and interventions to promote affordable housing, protect homeownership, and reduce speculation. Specifically, policies to reduce and stabilize housing prices, known as "cooling measures" or "home purchase restrictions," have been implemented in several countries. ${ }^{1}$

In China, housing prices have increased dramatically since the housing privatization reforms in the late 1990s. The average price of commercial housing in urban China has increased from 1,854 RMB per square meter in 1998 to 9,310 RMB per square meter in 2019, more than tripling in the past 20 years. The rapid increase in housing prices has aroused the Chinese government's concern about housing affordability and potential financial risks such as an asset bubble in the real estate sector. In 2010-2011, the central and local governments started to implement a set of austere housing market interventions, a policy known as home purchase restrictions (HPR), which includes directly restricting the number of real estate properties that a household can purchase based on household registration (Hukou) and the number of years of continuous deposit in the social security account, as well as other regulations such as increasing the minimum down payment ratio.

Most existing studies on the HPR focus on its impact on equilibrium outcomes of housing prices and sales. However, little is known about how such policy interventions separately affect demand and supply, such as consumers' preference and real estate developers' pricing strategy, which, in turn, determine the eventual market outcome. In this paper we analyze the impact of the HPR on real estate developers and consumers and how their responses affect equilibrium prices and sales in the housing market. Specifically, we evaluate the effectiveness of the HPR by estimating a structural model of housing demand and supply using project-level sales data on newly constructed condominium units sold by developers to individual buyers in five large

\footnotetext{
${ }^{1}$ For example, Toronto (Canada) has implemented Fair Housing Plan since April 2017, whichimposes a 15\% nonresident speculation tax for foreign housing purchasers. New Zealand passed the Overseas Investment Amendment Bill in August 2018, which states that foreigners are not eligible to purchase resale houses. Between September 2009 and December 2013, Singapore implemented a series of government interventions to cool down its housing market, such as introducing and increasing the Seller's Stamp Duty and Buyer's Stamp Duty (Deng et al., 2018).
} 
Chinese cities: Beijing, Shanghai, Guangzhou, Hangzhou, and Wuhan. ${ }^{2}$ We also conduct counterfactual analysis to quantify the contributions of various factors to the market outcome and examine the associated welfare implications. ${ }^{3}$

Our model applies the standard empirical industrial organization framework to housing markets (Berry, 1994; Berry and Jia, 2010). On the demand side, we treat projects as differentiated products and apply a discrete choice model to describe households' home purchase decisions. On the supply side, our baseline model assumes that real estate developers compete with one another by playing a standard Bertrand pricing game on offered residential projects. We also experiment with alternative assumptions on firms' conduct: assuming the market is more competitive or less competitive than the baseline model. Supply and demand jointly determine the housing market's equilibrium price and quantities. Following the comparative static analysis approach of Berry and Jia (2010), we estimate the equilibrium model using data from the pre-policy period and the postpolicy period and then evaluate changes in the estimation results and their implications.

Our estimation results show that the overall housing demand in most cities becomes less price elastic after the policy intervention, which suggests that the policy might meet its goal of driving out speculative investors in the housing market. Also, our estimation results in the real estate developers' cost structure suggest that they are eager to sell homes more quickly through lower pricing, which might indicate that they face tighter financial constraints after the HPR is implemented. Our counterfactual analysis suggests that the implemented HPR may lead to substantial consumer welfare loss because it changes the structure of demand and hence developers' incentives. Alternative policies that keep the structure of demand unchanged, such as a random lottery, would improve consumer and social welfare in some cases. The findings shed light on how to design housing market interventions that are effective without incurring significant welfare loss.

Our study contributes to the literature on the HPR (or other policies) in housing market. Existing studies on the HPR in China or cooling measures in other countries mostly focus on its

\footnotetext{
${ }^{2}$ Although the data contain many cities, we only use these five cities in structural estimation for two reasons. First, most cities' data do not contain sufficient observations from the pre-HPR period. Second, our market size calculation partly relies on the assumption that the HPR imposes different restrictions for migrants and local residents. Smaller cities usually do not have sufficient numbers of migrants in the household survey data we use to calibrate market size change. We acknowledge that housing price patterns could be different in other parts of China.

${ }^{3}$ A "project," also called a residential complex, comprises a building or group of buildings, and each building has more than one single residential unit. These buildings share common areas, services, and facilities.
} 
overall effects on the equilibrium outcome, i.e., housing price and sales quantity (Deng et al., 2018; Jia et al., 2018; Sun et al., 2017), and very few look at the impact on supply and demand separately (except Somerville et al., 2020). The general finding is that implementing HPR immediately "freezes" the housing market: the quantity sold is reduced sharply and the price increase is slowed down in the short run. For example, Sun et al. (2017) use regression discontinuity to find that the HPR in Beijing caused a $17 \%-24 \%$ decrease in resale price and a $50 \%-75 \%$ reduction in transaction volume. Deng et al. (2018) use a regression discontinuity method and find that cooling measures in Singapore reduce housing price by $10 \%-15 \%$. Jia et al. (2018) investigate the effect of the HPR on housing prices in Guangzhou using a hedonic housing price model. Du and Zhang (2015) develop a theoretical model and used a counterfactual analysis to examine the treatment effect of the HPR and trial property taxes in Shanghai and Chongqing on housing prices. The most recent paper by Somerville et al. (2020) is among one of the few that have looked at the effect from both demand side and supply side in four cities. They measure the effect of the HPR on supply using government land auction data and a difference-in-differences approach. They find that the HPR works mainly through demand but not through the land market or developer supply response because there is no change in land prices or the number of land auctions. Our study differs from theirs by uncovering the intermediate channels through which how consumers and firms adjust their behavior in response to policy change, which in turn affects housing market prices and quantity sales.

Our study also contributes to the empirical study of housing markets using a structural model. Although structural models are widely used in many industries, such as automotive or airline, few are applied to housing markets, and most of these models only focus only on either housing demand or supply, but not both. For example, Bajari et al. (2013) estimated a dynamic model of housing demand with nonconvex adjustment costs, credit constraints, and income and housing price uncertainties using the Panel Study of Income Dynamics. Bayer et al. (2007) developed a sorting model of household discrete choices of residence to describe household preferences for school and neighborhood attributes. They find that households are willing to pay about $1 \%$ more in housing when local school performance increases by 5\%. Patrick et al. (2016) developed a dynamic model of neighborhood choice and examined marginal willingness to pay for air pollution, crime, and racial composition using housing transaction data in San Francisco from 1994 to 2004. The literature on housing supply is relatively scarce. Murphy (2018) developed a dynamic 
model of housing supply with forward-looking landowners and find that forward-looking behavior significantly reduced the housing supply elasticity. The Chinese new home market provides a unique opportunity for us to investigate the incentives of both buyers (demand) and developers (supply) using a structural model.

The rest of the paper is organized as follows. In Section 2, we provide institutional background on China's housing market and the HPR. We describe the data in Section 3 and show reduced-form analyses in Section 4. Section 5 presents our model specification and estimation strategy. Section 6 shows estimation results and counterfactual analyses. Section 7 concludes.

\section{Background}

\subsection{China's Housing Market Overview}

China experienced nationwide privatization of public housing stocks in the late 1990s. Soon after the housing reform, China embraced a remarkable housing market boom that lasted for about two decades. As the urban housing stock in China has been estimated at around 33.6 billion square meters at the end of 2019, one can roughly set the total housing market value in urban China at around 130 trillion CNY. This number is nearly twice China's GDP in 2015, which was 67 trillion CNY. These factors make Chinese housing market one of the largest in the world. The Chinese housing market consists of both the new home market and resale market. Unlike many developed countries, in China the new home market has dominated the resale market in terms of market size: new construction accounted for over $80 \%$ of total housing sales in the early 2000 s right after the housing privatization reforms, and in 2017 it still accounted for about $60 \%$ of total sales.

In this paper we focus on the new home market. New homes are built by real estate developers who obtain land from the government. ${ }^{4}$ Once a real estate developer pays to acquire a land parcel (for residential development), it starts to build residential complexes (mostly condos) and sell to households.

\footnotetext{
${ }^{4}$ The Chinese government owns all urban lands and can lease them to other stakeholders in the housing market (see Wu et al., 2012). Every five years, the central government issues a five-year master plan to allocate agricultural land to local governments and designates the specific usage for each land parcel, such as residential, commercial, or industrial land. Then local governments transfer land usage rights to developers through negotiations or public land auctions. Transactions via public auctions can be done by regular English auctions, two-stage auctions, or sealed bidding auctions (see Cai et al., 2013). The 1988 constitutional amendment allowed a purchase of land parcel for up to 70 years for residential projects (Deng et al., 2012). In 2004 the central government required all residential, commercial, or industrial land sold by auctions, and by 2014, 93\% of land sales were conducted by auction. The upper limit of floorto-area ratio and designated usage are specified before the auction. The winning bidder is announced publicly and posted to the government website.
} 
During housing boom periods, real estate developers have strong incentives to acquire land parcels in areas where they expect a large housing price appreciation, especially in first-tier cities. However, because it takes several years from purchasing the land parcel to eventually completing the housing projects, many developers face stringent financial constraints in the development/sales process. To get over the financial hurdle, developers use various ways to raise funds (e.g., presale, borrow from commercial banks, trusts, peer-to-peer lending, etc.). Given the high financial leverage ratio, the developers may have strong incentives to sell housing projects quickly to avoid financial cost. However, on the other hand, developers may want to hold housing inventory and wait for price appreciation so that they can earn more profit. Which incentive dominates is an empirical question that the following analysis will explore.

\subsection{Housing Market Interventions in China}

On April 17, 2010, the State Council of the People's Republic of China issued a public announcement that it had decided to take firm action to control prices. On April 30, 2010, Beijing was the first city to announce HPR policies. This was unanticipated because the HPR had never been implemented in China, it has rarely been instituted in other countries, and there was no pilot program before the announcement.

Under Beijing's initial HPR, only one home purchase was allowed for each household after April 30, 2010; on February 15, 2011, the Beijing government amended the HPR that imposed distinct restrictions on households with Beijing Hukou and those without. ${ }^{5}$ For a household with a Beijing Hukou, two home purchases were allowed. For a household without a Beijing Hukou, only one home purchase was allowed ${ }^{6}$ and at least one household member was required to have five years' continuous deposit record in a social security account (amounting to five years' work experience without a gap).

Following Beijing, many other cities started to implement HPR policies: by the end of 2010, 19 cities, including Shanghai, Guangzhou, and Hangzhou, implemented HPR policies; and by November 2011, 46 cities implemented them. Although HPR policies varied across different cities

\footnotetext{
${ }^{5} \mathrm{Hukou}$ is a permit for permanent residency in the city, which gives an individual access to various welfare benefits such as medical insurance, social security, and children's education in public school.

${ }^{6}$ On March 30, 2013, another policy intervention was introduced: those who were single and had a Beijing Hukou were only allowed to purchase one house instead of two. On October 22, in the same year, each family with a Beijing Hukou could only purchase one house regardless of marital status. These harsh restrictions were not relaxed until September 30, 2016, when the government announced that families with a Beijing Hukou would be allowed to purchase two houses again.
} 
in certain aspects, they were largely similar to the one in Beijing: households with a local Hukou were only allowed to make one home purchase if they already owned a home, and they were not allowed to purchase any more homes if they already owned two or more; households without a local Hukou could only purchase one home if they had made continuous deposits to a social security account for at least one year. ${ }^{7}$ The fact that the HPR applied different rules to nonresidents and residents could cause a structural change in the demand; for instance, if non-residents tended to purchase for speculative purposes, then driving them out would imply that the overall market demand could become more inelastic after the HPR was implemented.

In addition to limiting the number of homes a household could purchase, local governments also tightened the regulations on down payment ratios and mortgage interest rates. For example, the down payment ratio of the second home had to exceed $60 \%$ of the baseline interest rate in most cities, and the mortgage loan interest rate had to be at least $110 \%$. Moreover, anecdotal evidence suggests there were some new regulations imposed on the supply side (i.e., real estate developers), such as higher deposit rates when acquiring land parcels and direct price caps on newly released condos. Because all these policy changes happened at about the same time, we treat them in our study as a part of the HPR and analyze their overall effects.

\section{Data Overview}

\subsection{Data Source}

The primary data we use for this study are project-level aggregation of new home transaction records from the Chinese Real Estate Index System (CREIS). The raw data cover more than 100 cities from 2009 to 2015; however, most cities' data do not contain sufficient observations from the pre-HPR period. Thus, we use data from only five cities-Beijing, Shanghai, Guangzhou, Hangzhou, and Wuhan - that cover both pre- and post-HPR periods in our structural analysis. Two administrative districts in Guangzhou-Zengcheng district and Conghua district-were not subject to HPR policies in 2010, and we exclude these two districts from all our analysis in Guangzhou. When performing the reduced-form analysis using difference-in-differences approach, we include another seven cities-Chongqing, Dongguan, Gu'an, Langfang,

\footnotetext{
${ }^{7}$ In 2014, China's real estate market began to cool down. In some underdeveloped cities, there was even a risk of a housing bubble bust. Thus, several local governments relaxed their HPR policies: by October 2014, about 40 cities had abolished or relaxed their HPR policies. Only Beijing, Shanghai, Guangzhou, Shenzhen, Zhuhai, and Sanya continued to impose the same restrictions. Although HPRs are generally considered temporary policies designed to cool down the housing market, because of a resurgence in housing prices, several cities, including Hangzhou and Nanjing, re-implemented HPR policies in the third quarter of 2016.
} 
Lianyungang, Tangshan, and Xianghe - to construct control groups. ${ }^{8}$

For each city-project-month observation, the data contain total square meters sold, number of units sold, and total sales revenue. The data also include project characteristics such as the name of the project, the name of the real estate developer, project location, construction area, floor-toarea ratio (FAR), greenness ratio, and property fee. We further aggregate data into city-projectquarter level averages because the project-month level quantity sales data contain many zeros that can lead to substantial biases to the structural estimation (see Gandhi et al. 2019 for details).

We complement the primary data with the China Family Panel Studies (CFPS) 2010. CFPS consists of biannual national representative panel data that covered around 15,000 households in 2010. It contains various information on demographics, whether an individual has a Hukou or not, and the number of houses a household owns. We use this data to measure the changes in market size and residence demographics after the HPR policy. Finally, we calibrate the market size using the total number of households each year in each city from the China Statistical Yearbook 2018 (compiled by National Bureau of Statistics of China).

\subsection{Summary Statistics}

In this section, we document some basic patterns in the aggregate transaction data and demographics data.

Table 1 provides summary statistics for the project characteristics and transactions in each of the five cities (Beijing, Shanghai, Guangzhou, Hangzhou, and Wuhan) for the pre-HPR period and the post-HPR period. ${ }^{9}$ First, there are large variations in project characteristics across the five cities. For example, FAR in Shanghai is much lower than in the other four cities, which suggests that lower-rise condo buildings are more popular in Shanghai. Second, most project characteristics - including FAR, the property fee, the green ratio, and whether the condo is decorated - do not change much (and there seems no clear pattern in the direction of changes) after the HPR is implemented, suggesting that the overall quality of homes remains rather stable after the HPR. Third, the last three rows of transaction information show significant changes in prices and sales after the HPR. In particular, average prices in Beijing, Shanghai, and Wuhan increase

\footnotetext{
${ }^{8}$ As a result of data availability, the starting period varies by city. The starting quarter is 2009 Q1 for Beijing, Gu'an, and Langfang. The starting quarter is 2008 Q1 for Hangzhou, 2008 Q4 for Wuhan, 2009 Q4 for Guangzhou, 2010 Q1 for Dongguan and Xianghe, 2010 Q2 for Tangshan and Lianyungang, and 2010 Q3 for Chongqing and Zhenjiang. The ending period for all cities is 2015 Q3.

${ }^{9}$ The HPR starting quarter in each city is as follows: 2010 Q2 for Beijing; 2010 Q4 for Shanghai, Guangzhou and Hangzhou; and 2011 Q1 for Wuhan.
} 
more than $35 \%$, and the corresponding quantities shrink substantially; both price and quantity increase in Guangzhou; and Hangzhou sales shrink substantially but price changes little. These changes in the equilibrium outcome suggest that demand- and supply-side conditions adjusted after the HPR was implemented.

\section{Table 1}

Summary Statistics of Projects

\begin{tabular}{|c|c|c|c|c|c|c|c|c|c|c|}
\hline & \multicolumn{2}{|c|}{ Beijing } & \multicolumn{2}{|c|}{ Shanghai } & \multicolumn{2}{|c|}{ Guangzhou } & \multicolumn{2}{|c|}{ Hangzhou } & \multicolumn{2}{|c|}{ Wuhan } \\
\hline & Before & After & Before & After & Before & After & Before & After & Before & After \\
\hline Floor-to-area ratio & 2.29 & 2.05 & 1.47 & 1.53 & 2.84 & 2.72 & 2.27 & 2.14 & 2.45 & 2.57 \\
\hline $\begin{array}{l}\text { Property fee } \\
\left(\mathrm{CNY} / \mathrm{m}^{2}\right)\end{array}$ & 3.01 & 2.92 & 2.26 & 2.70 & 1.96 & 2.39 & 2.98 & 2.37 & 1.51 & 1.94 \\
\hline Green ratio $(\%)$ & 0.34 & 0.32 & 0.40 & 0.39 & 0.32 & 0.39 & 0.30 & 0.31 & 0.34 & 0.34 \\
\hline $\begin{array}{l}\text { Total number of } \\
\text { units per project }\end{array}$ & 2,043 & 1,871 & 1,164 & 1,010 & 2,173 & 2,506 & 1,569 & 1,426 & 2,207 & 2,691 \\
\hline Whether decorated & 0.37 & 0.29 & 0.25 & 0.26 & 0.62 & 0.44 & 0.29 & 0.22 & 0.17 & 0.14 \\
\hline $\begin{array}{l}\text { Total area } \\
\text { transacted (square } \\
\text { meter) }\end{array}$ & 43809 & 39678 & 30420 & 20286 & 32716 & 41327 & 34893 & 19716 & 29979 & 26002 \\
\hline $\begin{array}{l}\text { Number of units } \\
\text { transacted per } \\
\text { project }\end{array}$ & 482 & 456 & 294 & 189 & 296 & 401 & 336 & 188 & 304 & 273 \\
\hline $\begin{array}{l}\text { Sales price } \\
\left(\mathrm{CNY} / \mathrm{m}^{2}\right)\end{array}$ & 13686 & 18077 & 15498 & 23146 & 12396 & 14520 & 14947 & 15496 & 5930 & 8436 \\
\hline
\end{tabular}

Notes: (a) For each city, the "before" ("after") column shows the average of each variable among all the projects and quarters before (after) HPR is implemented. (b) Property fee and sales price are CNY per square meter.

Table 2 shows the overall changes of market structure after HPR. Total numbers of both projects and developers decreased substantially in Beijing, Shanghai, Guangzhou, and Wuhan but increased in Hangzhou. To examine changes in market concentration, we further calculate the Herfindahl-Hirschman Index (HHI) before and after HPR. ${ }^{10}$ From the HHI results, we can see that, although HPR drives out some developers in Beijing, Shanghai, Guangzhou and Wuhan, the markets become less concentrated, suggesting that the surviving developers may not necessarily have gained more market power after HPR. These changes in market structure could affect each developer's pricing and sales strategies, which in turn affect equilibrium price and quantity.

\footnotetext{
${ }^{10} \mathrm{HHI}$ is calculated as the summing of the square of the market share of each firm (or each project) in the market.
} 


\section{Table 2}

Summary Statistics of Market Structure

\begin{tabular}{lcccccccccc}
\hline & \multicolumn{2}{c}{ Beijing } & \multicolumn{2}{c}{ Shanghai } & \multicolumn{2}{c}{ Guangzhou } & \multicolumn{2}{c}{ Hangzhou } & \multicolumn{2}{c}{ Wuhan } \\
\hline & Before & After & Befor & After & Befor & After & Before & After & Befor & After \\
\hline No. of projects & 110 & 50 & 96 & 51 & 72 & 26 & 22 & 30 & 64 & 55 \\
No. of developers & 63 & 28 & 62 & 33 & 48 & 17 & 16 & 22 & 33 & 29 \\
Project HHI & 81 & 132 & 70 & 62 & 203 & 181 & 340 & 115 & 73 & 45 \\
Developer HHI & 212 & 254 & 164 & 138 & 438 & 347 & 410 & 207 & 292 & 153 \\
\hline
\end{tabular}

Notes: (a) The numbers are averages across quarters. (b) The Herfindahl-Hirschman Index (HHI) is calculated as the sum of squares of market shares of projects or developers and is scaled up by 10,000 .

Figure 1 presents quarterly time series of average price per square meter and average transaction volumes across all projects in Beijing between 2009 Q1 and 2015 Q3. Graphs for the other four cities are presented in Figures A1-A4 in the Appendix. The vertical line indicates the starting quarter of HPR. Transaction volumes in all five cities declined sharply immediately after the HPR implementation, while prices continued to increase except in Hangzhou. This suggests that although the HPR cools down the market by reducing transactions, it does not effectively achieve the primary policy goal of stabilizing housing prices. $^{11}$

${ }^{11}$ The unusual increase in transaction volumes in the fourth quarter of 2012 is probably due to a high discount in interest rate of housing provident fund loans. The sudden drop in sales of the subsequent quarter could be due to the changes in capital gains tax announced in February 2013, when the government increase the capital gains tax with a holding period less than five years. 


\section{Figure 1}

\section{Trends in Sales Prices and Transaction Volumes in Beijing}

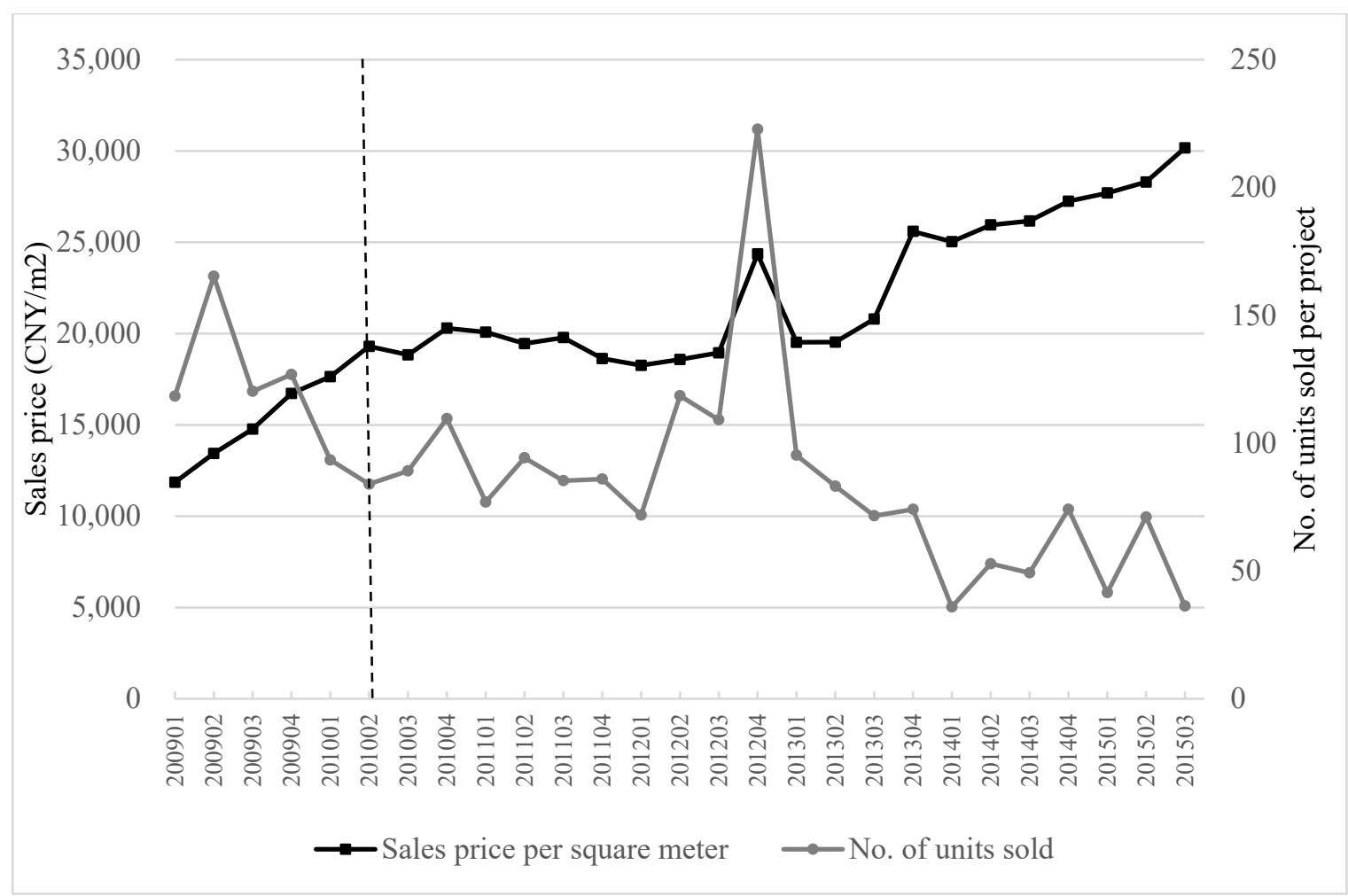

Next, we summarize information from the CFPS data that will be used for our analysis. Table 3 presents the fractions of local and migrant households that own no house, one house, or two or more houses. ${ }^{12}$ This information will be used to calibrate the change in market size after HPR in our structural estimation.

\footnotetext{
${ }^{12}$ There are few migrants in Hangzhou, and because the sample size is small, no migrants own houses. The overall samples for Beijing and Wuhan are also small. However, this is the only publicly available dataset that covers all five sample cities, contains information on the number of houses owned, and was available in the year before the HPR. Other data either do not provide information on number of houses owned (e.g., census data), were not available before 2010 (e.g., China Household Finance Survey), or do not cover the five sample cities (e.g., Urban Household Survey). Note that we use CFPS only to get the fraction of each category, which is used to calculate the percentage change of market size. Then we multiply the actual total number of households obtained from Statistical Yearbook by the percentage change calculated from CFPS.
} 


\section{Table 3}

Distribution of Households by Hukou Status and Number of Houses Purchased

\begin{tabular}{lllllll}
\hline Hukou & No. of & Beijing & Shanghai & Guangzhou & Hangzhou & Wuhan \\
\hline Migrant & 0 & $16 \%$ & $7 \%$ & $7 \%$ & $2 \%$ & $8 \%$ \\
Migrant & 1 & $17 \%$ & $11 \%$ & $9 \%$ & - & $23 \%$ \\
Migrant & 2 or more & $5 \%$ & $4 \%$ & $4 \%$ & - & $3 \%$ \\
Native & 0 & $26 \%$ & $12 \%$ & $12 \%$ & - & $11 \%$ \\
Native & 1 & $30 \%$ & $55 \%$ & $56 \%$ & $88 \%$ & $45 \%$ \\
Native & 2 or more & $5 \%$ & $11 \%$ & $12 \%$ & $10 \%$ & $11 \%$ \\
\hline
\end{tabular}

Notes: (a) This table is based on the China Family Panel Study (CFPS) 2010. (b) Each column sums up to $100 \%$. (c) The total number of households in the CFPS sample are 76 in Beijing, 1,120 in Shanghai, 60 in Hangzhou, 113 in Guangzhou, and 66 in Wuhan.

We group all households into the six categories in Table 3, then indicate which groups are no longer eligible for home purchase after the HPR, based on the city specific HPR rules. The rules are the strictest in Beijing, and we specify that all migrants and native with two or more homes are not eligible for home purchase after HPR. Therefore, after the HPR, the sample only includes natives with zero or one home. In Shanghai, Guangzhou, and Wuhan, after the HPR, only natives with zero or one home and migrants with zero homes are eligible for home purchase. Hangzhou has relatively relaxed HPR policies compared with the other four cities. As the rule suggests, regardless of Hukou status, any household is eligible to purchase only one new home. Therefore, we assume that migrants with two homes and natives with two homes drop out of the market after HPR.

Table 4 displays changes in several important demographics before and after HPR in each city based on the sample of households from the CFPS data. We find that after HPR, potential buyers remaining on the market generally are older, have lower income, and are less educated than the pre-HPR period. 


\section{Table 4}

Demographic Characteristics Before and After HPR

\begin{tabular}{llllccc}
\hline \multirow{2}{*}{ Beijing } & Age & $\begin{array}{c}\text { Total } \\
\text { family }\end{array}$ & $\begin{array}{c}\text { Family } \\
\text { size }\end{array}$ & $\%$ married & $\begin{array}{c}\% \text { some college } \\
\text { or above }\end{array}$ \\
& Aftere & 45.7 & 87,322 & 2.6 & $76 \%$ & $40 \%$ \\
Shanghai & 57.8 & 61,730 & 2.9 & $78 \%$ & $20 \%$ \\
& Before & 48.7 & 71,720 & 3.1 & $84 \%$ & $22 \%$ \\
Huangzhou & After & 51.2 & 60,599 & 3.0 & $82 \%$ & $17 \%$ \\
& Before & 42.5 & 60,258 & 3.7 & $91 \%$ & $24 \%$ \\
\multirow{2}{*}{ Wuhan } & After & 44.4 & 58,036 & 3.6 & $88 \%$ & $27 \%$ \\
& Before & 51.9 & 39,029 & 3.7 & $84 \%$ & $6 \%$ \\
& After & 52.1 & 37,256 & 3.7 & $86 \%$ & $4 \%$ \\
& Before & 42.8 & 49,195 & 3.4 & $90 \%$ & $31 \%$ \\
\hline
\end{tabular}

Notes: (a) This table is based on the China Family Panel Study (CFPS) 2010. (b) The total number of households in the CFPS sample are 76 in Beijing, 1,120 in Shanghai, 60 in Hangzhou, 113 in Guangzhou, and 66 in Wuhan.

\section{Reduced-Form Analysis}

Before introducing the structure model, we first provide some empirical evidence concerning the impact of the HPR on housing prices and sales using the time-varying difference-in-differences (DID) approach. The treatment group includes all five cities summarized in Table 1. The control group includes the following seven cities that had not implemented HPR: Chongqing, Dongguan, Gu'an, Langfang, Lianyungang, Tangshan, and Xianghe. ${ }^{13}$

We estimate the following DID regression model:

$$
y_{j t}=\beta_{0}+\beta_{1} \text { Treat }_{j} * \text { After }_{t}+\beta_{2} X_{j t}+\mu_{j}+\delta_{t}+\varepsilon_{i t},
$$

where $y_{j t}$ is outcome variable, either log price or log transaction volume for project $j$ in yearquarter $t$. The dummy variable Treat $_{j}$ indicates whether a project belongs to a city with HPR

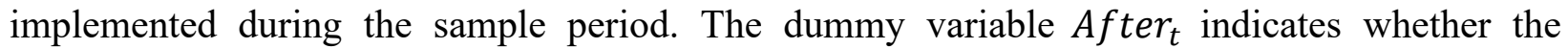
transaction quarter follows the policy implementation dates in each city. $\mu_{j}$ is project-level fixed effect, and $\delta_{t}$ is year-quarter fixed effects. The key variable of interest is the interaction term

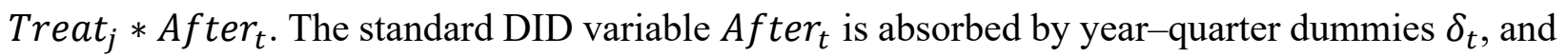

${ }^{13}$ As most non-HPR cities are small and lack good transaction data in early years, our choice of control cities is rather limited. 
Treat $_{j}$ is absorbed by project dummies. $X_{j t}$ controls for average condominium size. In an alternative specification, we further control time trend $D$, which equals to $1,2, \ldots$ if the transaction is one quarter, two quarters, ..., after policy implementation, and equals to 0 for pretreatment periods. Standard errors are clustered at the city level.

Table 5

Impact of HPR on Prices and Transactions, Difference-in-Differences Analysis

\begin{tabular}{lcccc} 
& $\log (P)$ & $\log (P)$ & $\log (Q)$ & $\log (Q)$ \\
\hline Treatment*after & $0.508^{* * *}$ & $0.412^{* * *}$ & $-0.401^{* * *}$ & $-0.341^{* * *}$ \\
& $(4.92)$ & $(3.88)$ & $(-3.81)$ & $(-4.00)$ \\
Log (home size) & $0.370^{* * *}$ & $0.367^{* * *}$ & $-0.617^{* * *}$ & $-0.615^{* * *}$ \\
& $(7.30)$ & $(7.41)$ & $(-4.24)$ & $(-4.20)$ \\
Post & & $0.010^{*}$ & & -0.007 \\
Constant & $7.276^{* * *}$ & $7.288^{* * *}$ & $5.452^{* * *}$ & $(-0.54)$ \\
& $(29.79)$ & $(30.26)$ & $(8.10)$ & $5.445^{* * *}$ \\
Project FE & $\checkmark$ & $\checkmark$ & $\checkmark$ & $(8.06)$ \\
Year-quarter FE & $\checkmark$ & $\checkmark$ & $\checkmark$ & $\checkmark$ \\
Observations & 80,167 & 80,167 & 80,167 & $\checkmark$ \\
R-squared & 0.712 & 0.713 & 0.360 & 80,167 \\
\hline
\end{tabular}

Notes: (a) This table presents DID regression results using quarterly aggregate of transaction data. (b) Columns $\log (\mathrm{P})$ reports regression results on log price (CNY per square meter), and columns $\log (\mathrm{Q})$ reports results on log quantity (number of units sold each quarter). (c) Treatment*After is the interaction between treatment dummy and implementation dummy. Post is implementation quarter dummy, which equals to $1,2, \ldots$ if one quarter, two quarters, ..., after the HPR implementation, and equals to 0 for pretreatment periods. All regressions control for log home size, project fixed effects, and year-quarter fixed effects. (d) The standard errors are clustered at the city level and are shown in parenthesis. (e) *** significant at $1 \%$ level.

Table 5 presents estimation results. We find that the effects of the HPR are consistent with existing studies in that transaction volumes decreased significantly. We find the housing price does not decrease as the government expected. We further examine how the effect of the HPR on housing prices and transactions evolves over time using the following regression model:

$$
y_{j t}=\sum_{s=-6}^{6} \beta_{s} \text { Treat }_{j} * \text { After }_{t+s}+\gamma X_{j t}+\mu_{j}+\delta_{t}+\varepsilon_{i t}
$$

The coefficients $\beta_{s}(s=0, \ldots, 6)$ capture the additional marginal response of the announcement quarter, one quarter, two quarters, ..., six quarters after the enforcement of the HPR. The coefficients $\beta_{s}(s=-6, \ldots,-1)$ measure the differences in trends on prices or quantities between 
the HPR cities and non-HPR cities in the pretreatment quarters. The estimates of pretreatment coefficients provide a test on whether the parallel trend assumption of the DID approach is satisfied.

Figure 2 plots the paths of the coefficients estimated from equation (2), and the brackets shows the corresponding 95\% confidence intervals. Prior to the HPR enforcement, there is no significant difference between the treatment cities and control cities at the $5 \%$ confidence intervals. This supports the validity of using the DID approach. After the HPR enforcement, we find significant increases in prices and decreases in quantities sold in the five cities that implemented the HPR, compared with the seven cities that did not implement the HPR.

We acknowledge the limitation of our DID analysis: the HPR treatment is not random. Cities with larger housing price increases are more likely to implement the HPR, and those are generally cities with faster economic growth. In the next section, we move forward by estimating a structural model of the market, which also allows us to examine the underlying mechanisms of the observed equilibrium changes.

Figure 2: The Dynamic Evolution of Prices and Quantities.

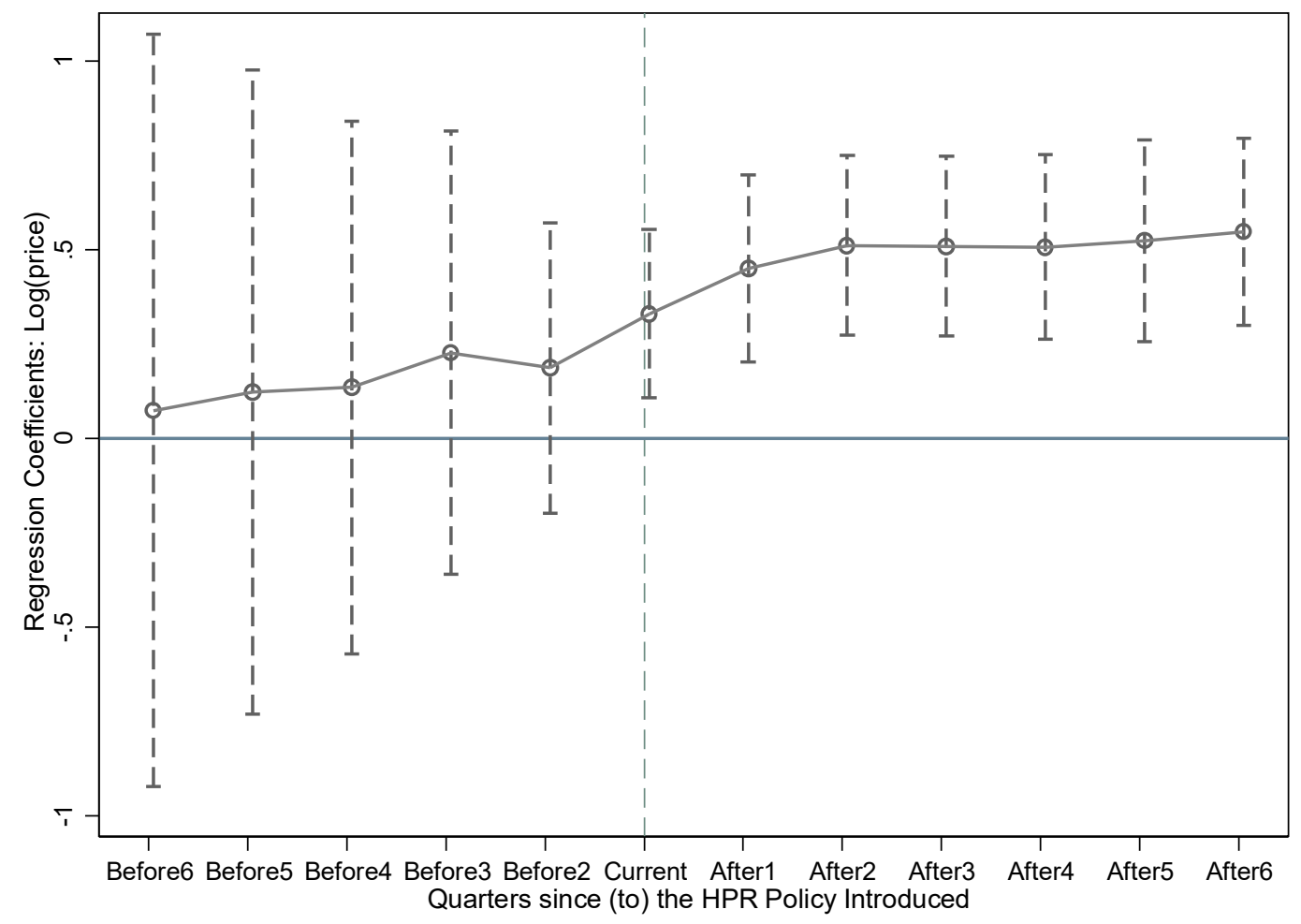




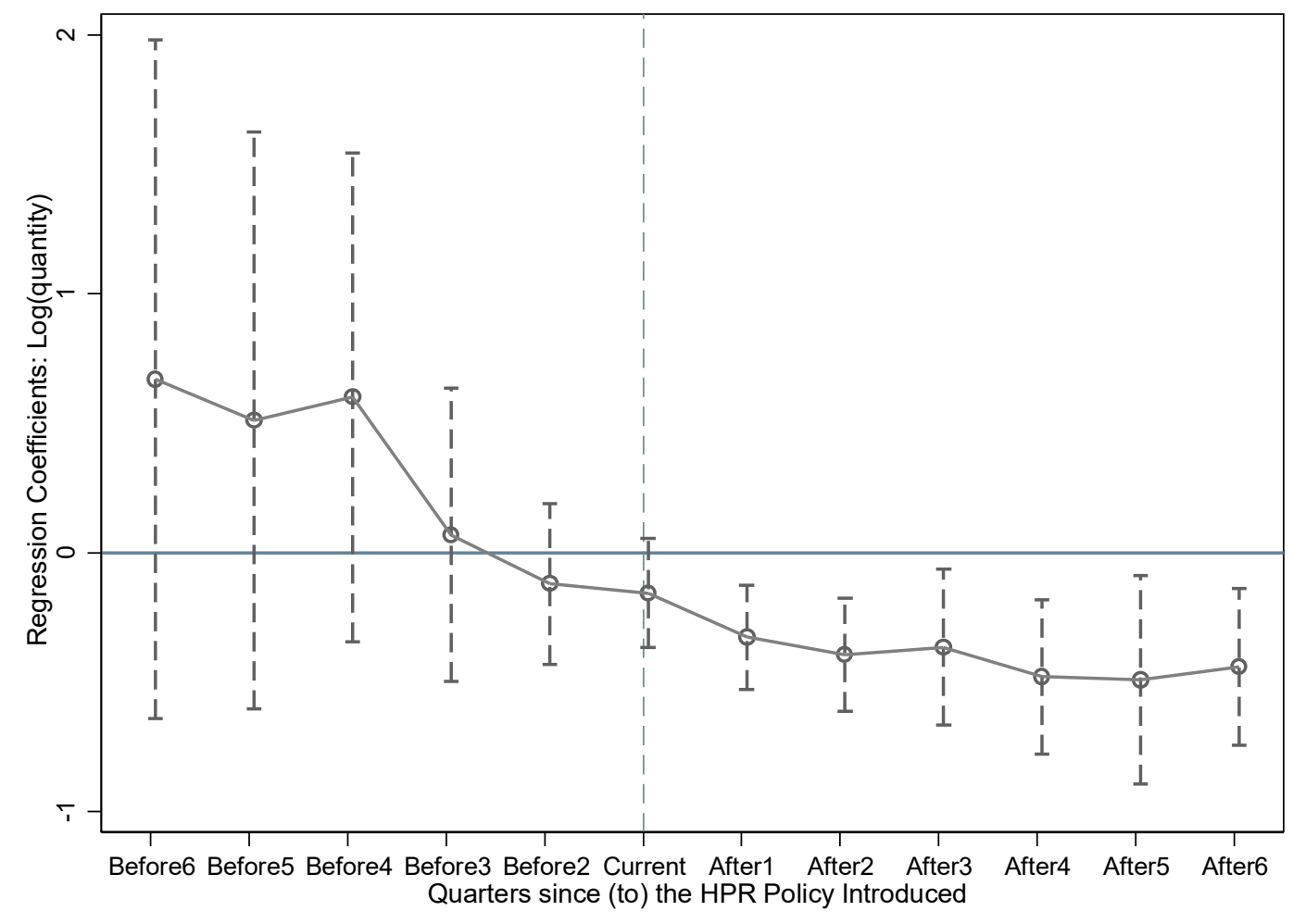

Notes: The figures plot the paths of coefficients along with their corresponding $95 \%$ confidence intervals of prices and quantities as estimated from equation (2). 


\section{Structural Model and Estimation}

In this section, we analyze the equilibrium outcomes before and after the HPR policy shock in China's housing market using the standard empirical IO framework for differentiated products market in the spirit of Berry et al. (1995); in particular, we follow Berry and Jia's (2010) approach to compare the ex-ante and ex-post market equilibrium.

\subsection{Demand Side}

For a given city, a resident's (or household's) decision on which home to purchase is inherently a discrete choice problem once a choice set (i.e., "market") is properly defined. Here we define a market as all the homes available for sale in a city-quarter pair. Market definition has implications for interpreting the single-choice model in the presence of multiple purchases. For example, if a household bought two homes within a quarter or in different quarters, then the model would treat it as two separate purchases by two ex-ante identical households.

To set up the discrete choice model, we define a product in any market as a "project-year" pair, which is mainly driven by our data structure. Given this product definition, a resident's decision on home purchase becomes a project choice problem. Also, our product definition treats one project in two years as two different products. This enables us to control any slow-varying characteristics of a project via product fixed effects in the estimation.

Let $\mathcal{T}_{t}=\left\{0,1, \ldots, J_{t}\right\}$ denote the set of products in market $t$, where the one labeled 0 refers to the "outside option," (i.e., not purchasing a new home [including not purchasing any home or purchasing a second-hand home]), and those labeled $j>0$ are the "inside goods."

The demand for a new home in a residential project is derived from a standard nested-logit random utility model (following Berry 1994). In other words, resident $i$ 's utility of buying a home in project $j$ in market $t$ is

$$
\begin{aligned}
u_{i j t} & =\delta_{j t}+\zeta_{i g t}+(1-\lambda) \epsilon_{i j t} \\
& =x_{j t}^{\prime} \beta-\alpha p_{j t}+\xi_{j t}+\zeta_{i g t}+(1-\lambda) \epsilon_{i j t},
\end{aligned}
$$

where $\delta_{j t}$ is the mean utility that is common to all residents, $x_{j t}$ is a vector of observed characteristics (including project dummies, year-quarter dummies, etc.), $p_{j t}$ is the average price per square meter,

$\xi_{j t}$ is an unobserved characteristic, $\zeta_{i g t}$ is a random variable common to all products in nest $g,{ }^{14} \lambda$ $\in[0,1)$ is the "nesting parameter" capturing the within-nest correlation between the choices, and

\footnotetext{
${ }^{14}$ The distribution function of $\zeta$ igt depends on the parameter $\lambda$.
} 
$\epsilon_{i j t}$ is an i.i.d. idiosyncratic preference shock following the standard Type I extreme value distribution. We normalize the mean utility of "outside option" as $\delta_{0 t}=0$ and let $\delta_{t}=\left(\delta_{1 t}, \ldots, \delta_{J t}\right)$. We define a nest as all the projects in an administrative district of a city and the outside option is the only member in group 0 .

The random utility model (1) implies the following demand system for each market $t$ :

$$
\begin{aligned}
s_{j t} & =\sigma_{j}\left(\delta_{t}, \lambda\right) \\
& =\sigma_{j \mid g}\left(\delta_{t}, \lambda\right) \sigma_{g}\left(\delta_{t}, \lambda\right), \forall j \in \mathcal{J}_{t},
\end{aligned}
$$

where $s_{j t}$ is the observed market share of product $j$ in market $t$ and $\sigma_{j}\left(\delta_{t}, \lambda\right)$ is the market share predicted by the model, and where $\sigma_{j}\left(\delta_{t}, \lambda\right)$ comprises the two components

$$
\begin{gathered}
\sigma_{j \mid g}\left(\delta_{t}, \lambda\right)=\frac{\exp \left[\delta_{j t} /(1-\lambda)\right]}{\sum_{k \in J_{g}} \exp \left[\delta_{k t} /(1-\lambda)\right]} \\
\text { and } \\
\sigma_{g}\left(\delta_{t}, \lambda\right)=\frac{\left(\sum_{k \in \mathcal{J}_{g}} \exp \left[\delta_{k t} /(1-\lambda)\right]\right)^{1-\lambda}}{\sum_{g}\left(\sum_{k \in J_{g}} \exp \left[\delta_{k t} /(1-\lambda)\right]\right)^{1-\lambda}},
\end{gathered}
$$

which are the within-group share of product $j$ and the group share of nest $g$, respectively.

In our application, the observed market share of each new residential complex is measured as:

$$
s_{j t}=\frac{q_{j t}}{M_{t}},
$$

where $q_{j t}$ is the number of homes sold in project $j$ in market $t$, and $M_{t}$ is the potential market size (number of consumers who make a choice from $\mathcal{T}_{t}$ ) calibrated using data from the Statistical Yearbook and CFPS. Specifically, for the pre-HPR period, we use the total number of households in a city to measure market size. After HPR, some households are no longer eligible for buying homes. According to HPR rules (which differ across cities), we calculate the proportion of households that remains on the market after the HPR based on the sample of households in the CFPS data summarized in Table 3. For example, in Beijing, we define the HPR-unaffected group as local residents with one home or fewer, as households with two or more homes cannot buy 
another because of the HPR. ${ }^{15}$

Following Berry (1994), we invert the demand system (4) to obtain the following estimation equation:

$$
\log \left(\frac{s_{j t}}{s_{0 t}}\right)=x_{j t}{ }^{\prime} \beta-\alpha p_{j t}+\lambda \log \left(s_{j \mid g, t}\right)+\xi_{j t},
$$

where $s_{j \mid g, t}$ is the observed within-group share of product $j$ in market $t$. And we impose the standard identifying assumption

$$
E\left[\xi_{j t} \mid Z_{j t}\right]=0, \forall j \in \mathcal{J}_{t}, \forall t
$$

where $Z_{j t}$ is a vector of instrumental variables.

Combining (5) and (6), we estimate the demand parameters using the standard 2SLS. The IVs are employed to address the endogeneity issue caused by the within-group share $s_{j \mid g, t}$ and price $p_{j t}$. The instrument for $s_{j \mid g, t}$ is standard: the number of products in nest $g$. For the price endogeneity issue, we apply "differential IVs" proposed by Gandhi and Houde (2019), which measure the relative location of a product in the characteristics space. ${ }^{16}$ In particular, we use $\sum_{k \neq j}\left(x_{k t}-x_{j t}\right)^{2}$ to construct IVs for price, and the summation is over the projects within the administrative district that product $j$ locates.

\subsection{Supply Side: Baseline Case}

After we estimate the demand model, we move on to consider the supply-side problem. As we focus on the new home market, the supply side comprises a group of competing real estate developers (firms) labeled by $f=1, \ldots, F_{t}$, each of which produces and sells multiple residential projects (products). The profit function of a firm $f$ in market $t$ is

$$
\pi_{j t}=M_{t} \sum_{j \in \mathcal{F}_{f}} A_{j t}\left(p_{j t}-m c_{j t}\right) s_{j t},
$$

where $\mathcal{F}_{f}$ is the set of projects developed by firm $f, A_{j t}$ is the average square meter per unit of project $j$ in market $t$, and $m c_{j t}$ is the associated marginal cost per square meter.

To complete the supply-side model, we need to make assumptions on the firms' conduct (i.e.,

\footnotetext{
${ }^{15}$ More accurate measures require information on social security deposits, or at least the number of years of work experience in the city. These are not available in the CFPS data. Therefore, we only proxy the HPR policy using migrant status and the number of houses owned.

${ }^{16}$ We also tried standard BLP (Berry, Levinsohn and Pakes, 1995) instruments (i.e., sum of product characteristics of other products owned by the same firm and sum of product characteristics of products owned by other firms); however, they fail to pass the standard weak IV test and typically generate implausible estimates (e.g., positive price coefficient).
} 
how the firms in a market compete). In the baseline case, we follow the most commonly used specification in the literature (see Berry et al., 1995 and subsequent studies) to assume that the firms set prices that maximize profit and are consistent with a static Bertrand-Nash equilibrium for differentiated products: in other words, the equilibrium prices (in matrix form) can be written as

$$
p_{t}=m c_{t} \underbrace{-\left[D_{p} \sigma\left(\delta_{t}, \lambda\right) \circ I\right]^{-1}\left(A_{t} \circ s_{t}\right)}_{\text {markup }},
$$

where $p_{t}, m c t, A t$, and $s t$ are vectors of the corresponding product level variables in market $t$ (e.g., $\left.p_{t}=\left(p_{1 t}, \ldots, p_{J t}\right)\right), D_{p} \sigma\left(\delta_{t}, \lambda\right)$ is the matrix of derivatives of market shares with respect to prices

$$
D_{p} \sigma\left(\delta_{t}, \lambda\right)=\left(\begin{array}{ccc}
\frac{\partial \sigma_{1}\left(\delta_{t}, \lambda\right)}{\partial p_{1 t}} & \cdots & \frac{\partial \sigma_{J}\left(\delta_{t}, \lambda\right)}{\partial p_{1 t}} \\
\vdots & \ddots & \vdots \\
\frac{\partial \sigma_{1}\left(\delta_{t}, \lambda\right)}{\partial p_{J t}} & \cdots & \frac{\partial \sigma_{J}\left(\delta_{t}, \lambda\right)}{\partial p_{J t}}
\end{array}\right)
$$

$I$ is the ownership matrix

$$
I_{j k}=\left\{\begin{array}{rr}
1, & j, k \in \mathcal{F}_{f} \\
0, & \text { otherwise },
\end{array}\right.
$$

and $\circ$ denotes the Hadamard (element-wise) product.

The firm's first-order condition (7) summarizes the pricing rule implied by the assumed model in an intuitive way: a project's price is jointly determined by its marginal cost and markup that measures the market power of the associated firm. Based on (7) and given the demand estimates, we can calculate the marginal costs for each product (defined by "project-year"):

$$
m c_{t}=p_{t}+\left[D_{p} \sigma\left(\widehat{\delta}_{t}, \hat{\lambda}\right) \circ I\right]^{-1}\left(A_{t} \circ s_{t}\right),
$$

where $\widehat{\delta}_{t}$ and $\hat{\lambda}$ are obtained from the demand estimates. And the derivatives matrix $D_{p} \sigma\left(\widehat{\delta}_{t}, \hat{\lambda}\right)$ can be calculated based on the demand model (2):

$$
\frac{\partial \sigma_{j}\left(\delta_{t}, \lambda\right)}{\partial p_{k t}}= \begin{cases}-\frac{\alpha}{1-\sigma} s_{j t}\left[1-\sigma \frac{s_{j t}}{s_{g t}}-(1-\sigma) s_{j t}\right] & j=k \\ \frac{\alpha}{1-\sigma} s_{k t}\left[\sigma \frac{s_{j t}}{s_{g t}}+(1-\sigma) s_{j t}\right] & k \neq j \text { are in the same group } g \\ \alpha s_{k t} s_{j t} & k \neq j \text { are in different groups }\end{cases}
$$

\subsection{Supply Side: Alternative Assumptions on Firms' Conduct}

One concern is that the baseline supply model with the assumed Bertrand competition (for differentiated products) does not reflect actual developer conduct in the market. On the one hand, the market may be more competitive than what the static Bertrand-Nash equilibrium predicts, 
which may be due to forward-looking behavior (i.e., dynamic pricing and investment [see Topel and Rosen, 1988] and/or contestable market hypothesis [see Baumol, 1986]). On the other hand, the actual market may be less competitive than the assumed Bertrand competition because of developers' tacit collusion, implicit financial affiliations, etc. To address this concern, we deviate from the baseline assumption of Bertrand competition and consider two alternative competition structures.

The first assumes that the market is more competitive (i.e., the markup is lower than the price equilibrium characterized by (7)). A simple way to account for this increased competitiveness is to add a "conduct parameter" $\gamma_{1} \in[0,1]$ in front of the markup term in (7):

$$
p_{t}=m c_{t}-\gamma_{1}\left[D_{p} \sigma\left(\delta_{t}, \lambda\right) \circ I\right]^{-1}\left(A_{t} \circ s_{t}\right)
$$

where a smaller $\gamma_{1}$ means a more competitive environment and $\gamma_{1}=0$ represents the extreme case of perfect competition with no markup. Note that adding a conduct parameter has a long tradition in the empirical IO literature; see, among others, Bresnahan (1989) and Genesove and Mullin (1998). Although it is usually considered a "reduced-form" way of introducing more flexible strategy interactions beyond the static Bertrand (or Cournot) competition, it seems sufficient for our current analysis, which serves as a robustness check for the baseline results.

The second competition structure is that the market is less competitive than the baseline case. This amounts to assuming that the firms not only care about their own profits but also internalize others' profits to a certain extent, with the extreme case being that all the firms in a market jointly maximize their total profit (i.e., full collusion). To account for such cases, we follow the literature on firm conduct and market structure (e.g., Nevo, 2001; Sudhir, 2001; Ciliberto and Williams, 2014, among others), to modify the ownership matrix I in the pricing equation (7) such that

$$
I_{j k}=\left\{\begin{array}{cc}
1, & j, k \in \mathcal{F}_{f} \\
\gamma_{2}, & \text { otherwise },
\end{array}\right.
$$

where $\gamma_{2} \in[0,1]$ measures how much each firm internalizes other firms' profits, with $\gamma_{2}=1$ being the full collusion case.

To take these alternative assumptions of firms' conduct to data, we fix the conduct parameter $\gamma_{1}\left(\right.$ or $\gamma_{2}$ ) at a particular value ${ }^{17}$ and then perform the empirical analysis (i.e., uncover the marginal costs and simulate counterfactual scenarios) in a way similar to the baseline case.

\footnotetext{
${ }^{17}$ Here, we do not estimate the conduct parameter because it is not clear how they can be separately identified in our setting (without cost side information); see Genesove and Mullin (1998) for more discussion on this issue.
} 


\subsection{Some Remarks on the Model}

We acknowledge that the model has several limitations. First, it is a static model and thus cannot explicitly account for potential dynamic incentives of households and real estate developers. This may generate biases to our estimates. For example, a household's home purchase decision may be driven by both the current and future housing prices (i.e., forward-looking behavior). Heuristically, the static demand model ignores the effects of expected future price on buyer's choice and this is similar to the omitted variable problem in a standard linear regression. Hence, if the omitted variable, e.g., expected future price, is positively correlated with the current price, then an OLS estimate of the price coefficient tends to bias toward zero. However, since we treat price (and within-group share) as an endogenous variable and form moment conditions using instrumental variables, this omitted variable will lead to biased estimates only when it is not (mean) independent of the instrumental variables.

Despite the above potential risk, the static model is sufficient to answer the questions we are after in this paper because all we want to do is compare the pre- and post-policy market equilibria and thus evaluate the policy impact. A dynamic model would help us to understand the transition better but add only limited value to our problem. Moreover, estimating a dynamic equilibrium model will pose computational challenges and thus may limit our ability to include a rich set of covariates (mostly fixed effects) in the empirical model. Nevertheless, analyzing the housing market with a fully dynamic competition model is an important direction for future research.

Also, we model the supply side as standard oligopolistic competition among profit maximization firms. Although we have considered alternative assumptions on firms' conduct, they are not sufficient to capture the potentially rich incentives that developers face in the market. For example, some state-owned developers in China might have other incentives beyond profit maximization (e.g., political responsibility) that could affect the nature of competition in the market. However, given that we do not have additional information/data, we decide to move forward with the standard model, and the results should be interpreted as a benchmark, with caveats.

Finally, in our demand estimation, we use nested logit instead of random coefficient logit. Though the latter can potentially capture richer preference heterogeneity and more flexible substitution patterns, it is computationally more challenging to estimate and more importantly requires more (and strong) instrumental variables to achieve identification. Unfortunately, we 
cannot find or construct such IVs from our available data.

\section{Estimation Results and Counterfactual Analysis}

\subsection{Estimation Results}

We divide the sample of each city into before- and after-HPR periods and estimate the demand model for each subsample separately based on equation (5) and (6). Table 6 presents the estimation results. ${ }^{18}$

The results are heterogenous across different cities. The price coefficient, which measures home buyers' price sensitivity, moves towards zero after the HPR for Beijing, Shanghai, Guangzhou, and Wuhan but becomes more negative for Hangzhou. Also, the estimates of the nesting parameter are quite large, with most greater than 0.5 , which means that residential complexes located in the same administrative district are close substitutes, whereas the substitution effects between homes located in different administrative districts are weak. The changes in the estimated nesting parameters caused by HPR show that the within-district correlation becomes weaker in Beijing, Shanghai, Hangzhou, and Wuhan, whereas it is the opposite for Guangzhou. Moreover, note that we include the product (project-year) and year-quarter fixed effects to control time-invariant and slow-varying project characteristics, as well as market level common shocks. Finally, the first-stage Sanderson-Windmeijer F-test shows that the instruments are not weak in general (except for the pre-HPR period of Guangzhou).

Next, we examine the fitness of our model by comparing the model-predicted prices and sales volume with transaction data. Figure A5 in the Appendix presents the fitted quarterly series of aggregate quantity versus the actual data. We find that the predicted values match the actual data reasonably well in most cases, although the model seems to slightly underestimate the actual demand (especially in Beijing and Wuhan). This may be due to the model limitations we discussed in the previous section.

Using the demand-side estimates, we calculate the price elasticities and show them in Table 7. Overall, demand becomes much less price elastic after HPR in all the cities except Guangzhou. This could have two related but different interpretations. One interpretation is that the composition or structure of aggregate demand has changed. As some consumers are not eligible for home

\footnotetext{
${ }^{18}$ Since it takes time for the market to adjust to the equilibrium status, as a robustness check, we drop the quarter when the policy implemented, or drop two quarters that include the policy implementation quarter and one quarter right after that and re-estimate demand model. The results are very similar to baseline results in Table 4 and thus, to conserve space, are not shown.
} 
purchase because of HPR regulation, consumers remaining on the market after the HPR are more price inelastic than those who are no longer on the market after the policy change. Another interpretation is that the consumers' preferences for housing attributes have changed after the HPR, even if the composition has not changed. Changes in price elasticity could be due to either interpretation or to both. 
Table 6

Demand Estimation Results

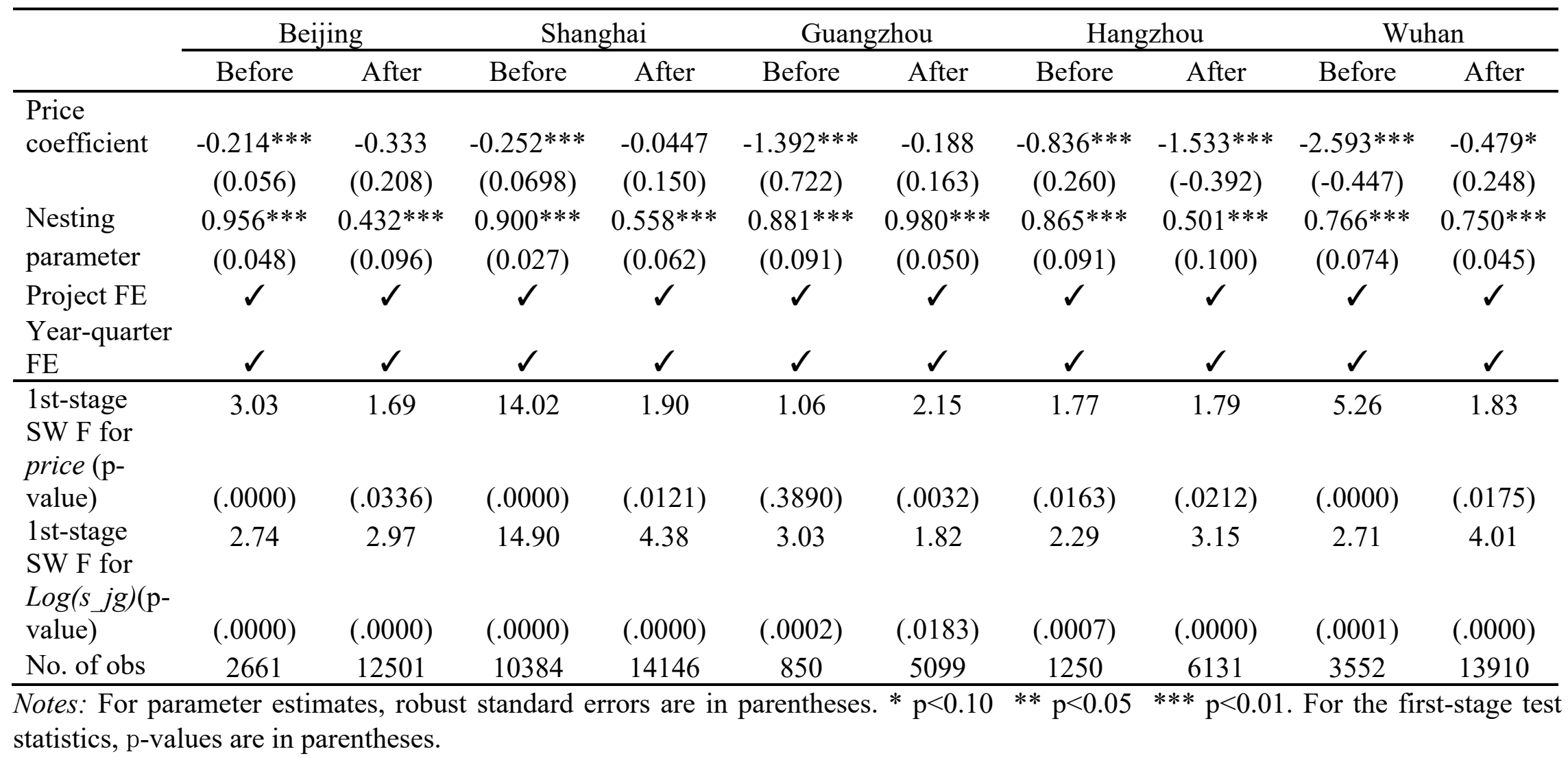


Table 7

Price Elasticities Before and After HPR

\begin{tabular}{|c|c|c|c|c|c|c|c|}
\hline & & \multicolumn{2}{|r|}{ Beijing } & \multicolumn{2}{|c|}{ Shanghai } & \multicolumn{2}{|c|}{ Guangzhou } \\
\hline & & Before & After & Before & After & Before & After \\
\hline \multicolumn{2}{|c|}{ Avg. own elasticity } & -7.280 & -1.219 & -3.818 & -0.269 & -14.380 & -16.263 \\
\hline Cross & Within & -0.168 & -0.015 & -0.116 & -0.005 & -0.484 & -0.495 \\
\hline \multirow[t]{3}{*}{ Elasticity } & Across & -0.000025 & -0.000056 & -0.000016 & -0.000005 & -0.000171 & -0.000028 \\
\hline & & \multicolumn{2}{|c|}{ Hangzhou } & \multicolumn{2}{|r|}{ Wuhan } & & \\
\hline & & Before & After & Before & After & & \\
\hline \multicolumn{2}{|c|}{ Avg. own elasticity } & -9.998 & -5.205 & -6.644 & -1.588 & & \\
\hline Cross & Within & -0.529 & -0.107 & -0.168 & -0.024 & & \\
\hline Elasticity & Across & -0.000166 & -0.000244 & -0.000230 & -0.000072 & & \\
\hline
\end{tabular}

Notes: (a) This table presents the price elasticities before and after HPR in each of the five cities. (b) "Within" refers to within nest cross-elasticity and "Across" refers to across-nest cross-elasticity, both are defined based on the derivatives in (7).

The first interpretation of composition change is partially supported by the demographic changes of potential buyers summarized in Table 4 in Section 3.2, which shows that the average buyer in the post-HPR period is older, has lower income, and is less educated (in terms of college degree) than in the pre-HPR period. To see this link more closely, we pool data from all five cities together and regress product-level price elasticities on the summary statistics on demographic variables shown in Table 4. The regression results, shown in Table A2 in the Appendix, suggest that older, lower income, and less-educated families' demand tends to be more inelastic to price changes in housing.

There are alternative explanations of why the demographics affect price elasticities in this particular way. For example, older and less-educated people may have less access to alternative options of financial investments (e.g., because of lack of financial literacy) and thus are willing to allocate more money to the housing market, which implies that their demand for housing is inelastic to price adjustments. Alternatively, given that the HPR limits the number of homes a household can purchase (depending on their residence and employment status), many speculative purchases, which are more likely to come from people with higher education and income, are driven out of the market. These people are usually more price sensitive as their primary purpose 
of home purchase is investment rather than actual need. In this case, HPR policy intervention does meet its goal of reducing speculative housing demand.

Given the limited and aggregated information on demographics, we cannot obtain clear evidence on whether the preference of the same group of buyers changes after HPR and thus cannot quantify the second interpretation. This is a limitation of the current analysis and we shall revisit this point in the counterfactual analysis.

Now let us turn to the supply-side estimates that inform us about the changes in the cost structure of real estate developers after HPR. Table 8 presents the changes in average marginal costs and markups for the three alternative assumptions on firms' conduct described in Section 5.2 and 5.3. In particular, "More Competitive" and "Joint Profit Maximization" refer to the two cases described in Section 5.3 with $\gamma_{1}=.5$ and $\gamma_{2}=1$, respectively. ${ }^{19} \mathrm{We}$ can see that, despite the different conduct assumptions, the results are qualitatively similar: corresponding to the changes in demand elasticities, the marginal costs in four cities fall after the policy intervention, whereas Guangzhou is the opposite. Note that there are a few cases, mostly for Shanghai in the after-HPR period, for which we cannot obtain marginal costs because of the inelastic price (absolute value of elasticity less than 1). ${ }^{20}$ However, these marginal costs would be 0 if we impose a nonnegative constraint, so this does not change the pattern regarding the direction of adjustments in the marginal costs resulting from HPR.

In Section 2.1 we mention that developers' construction cost is small and stable relative to the financial cost (of holding housing units). A decrease in marginal cost suggests that there is an increase in holding cost because of financial constraints. Developers have stronger incentive to lower the price and sell more quickly to maintain sufficient capital flow and repay debts. An alternative explanation for the increased financial costs is that the HPR implementation is associated with other policies that strengthen regulations in the financial sector, which leads to tightened liquidity. The exception is Guangzhou, where the overall demand becomes more elastic after the HPR (different from other cities). One potential interpretation is that since two administrative districts in Guangzhou did not implement the HPR (which we exclude from our analysis), developers may not face the same financial pressure or tightening of liquidity that other

\footnotetext{
${ }^{19}$ We also tried several other values of $\gamma_{1}$ and $\gamma_{2}$. They yield qualitatively similar results in terms of deviations from the baseline case results.

${ }^{20}$ For these cases, the firms' profit maximization problem is not well-defined (not concave) and thus we cannot use the first-order condition (5), which does not hold, to back out marginal costs.
} 
cities do because they can borrow money from the non-HPR districts. Another potential reason is that Guangzhou sets an explicit price ceiling. ${ }^{21}$ Thus, the observed prices do not reflect the optimal pricing decisions of developers.

\section{Table 8}

Average Marginal Cost and Markup Before and After HPR

\begin{tabular}{|c|c|c|c|c|c|c|c|c|c|c|c|}
\hline \multirow{2}{*}{$\begin{array}{l}\text { Firm's } \\
\text { conduct }\end{array}$} & & \multicolumn{2}{|c|}{ Beijing } & \multicolumn{2}{|c|}{ Shanghai } & \multicolumn{2}{|c|}{ Guangzhou } & \multicolumn{2}{|c|}{ Hangzhou } & \multicolumn{2}{|c|}{ Wuhan } \\
\hline & & Before & After & Before & After & Before & After & Before & After & Before & After \\
\hline \multirow{3}{*}{ Baseline } & Marginal & 1.30 & 0.38 & 1.15 & - & 1.18 & 1.64 & 1.53 & 1.40 & 0.52 & 0.31 \\
\hline & Cost & & & & & & & & & & \\
\hline & Markup (\%) & 23.10 & 156.52 & 40.96 & - & 9.38 & 8.66 & 12.83 & 25.24 & 18.63 & 85.32 \\
\hline \multirow{3}{*}{$\begin{array}{c}\text { More } \\
\text { competitive }\end{array}$} & Marginal & 1.4 & 1.26 & 1.36 & - & 1.22 & 1.7 & 1.61 & 1.56 & 0.57 & 0.57 \\
\hline & Cost & & & & & & & & & & \\
\hline & Markup (\%) & 11.55 & 78.26 & 20.48 & - & 4.69 & 4.33 & 6.41 & 12.62 & 9.31 & 42.66 \\
\hline \multirow{3}{*}{$\begin{array}{l}\text { Joint profit } \\
\text { maximization }\end{array}$} & Marginal & 0.97 & - & 0.71 & - & 1.08 & 1.52 & 1.35 & 1.22 & 0.44 & - \\
\hline & & & & & & & & & & & \\
\hline & Markup (\%) & 56.17 & - & 83.06 & - & 19.04 & 18.43 & 25.45 & 38.88 & 34.95 & - \\
\hline
\end{tabular}

Notes: "More competitive" refers to the first case described in Section 5.3 with $\gamma_{1}=.5$. "Joint profit maximization" refers to the second case described in Section 5.3 with $\gamma_{2}=1$. The missing values correspond to the cases with inelastic demand, where we cannot use the first-order condition to obtain marginal costs and markups. However, with a nonnegative constraint on marginal costs, the marginal costs for these cases would be 0 (with markups being 100\%).

We conducted several robustness checks on demand estimates and firms' conduct. First, for market size calculation, we tried alternative ways of calculating the proportions of residence by migration status and number of houses owned, e.g., using individual-level rather than householdlevel data, or using the province-level sample to proxy the city-level sample to enlarge the sample size for less noise in calculating the categorical probabilities (but potentially more biased because a province may not be representative for one particular city in it). The results are all very similar, so in the main analysis we used a household-level sample. Second, we modified the rules according to which groups of individuals would drop out of the sample after the HPR. Third, for firms'

\footnotetext{
${ }^{21}$ The government provides the upper limit of transaction price of different types of housing. If the actual price exceeds the price guidance, a formal contract will not be signed or its signing will be postponed. According to the data, some houses sell more slowly than before.
} 
conduct, we tried several other values of $\gamma_{1}$, which yielded qualitatively similar results.

\subsection{Counterfactual Analysis}

In this section we conduct three counterfactual analyses to illustrate the implications of our estimation results. The first two counterfactual analyses quantify the contributions of changes on the demand and supply side, respectively. In the first counterfactual, we assume that the developer's cost structure is fixed so that the HPR only affects demand. The second counterfactual assumes that only the developer's cost structure adjusts while the demand side remains unchanged. In the third counterfactual analysis, we try to mimic a scenario where the current HPR is replaced by a housing lottery scheme (i.e., the eligibility of purchasing a house is determined by a random lottery instead of the current restrictions that rely on Hukou status and the number of years of deposits to social security account). To do this, we let the market size and supply side change while keeping the demand parameters unchanged because, under a lottery scheme, consumers randomly drop out of the market; thus, the market size shrinks by the same amount, but the demand parameters do not change.

For each of the counterfactual designs, we compute the new after-HPR equilibrium prices and quantities by jointly solving the demand and supply system. Then, we calculate the changes resulting from the HPR and compare them with the actual changes. Table 9 summarizes the results for the counterfactual simulations given the baseline case specification of the supply side (see Section 5.2). The results for Beijing are based on two quarters before and after the HPR (because the Beijing sample covers only two quarters before the HPR); and for other cities, we use four quarters before and after the HPR implementation quarter for calculating the results.

In the first counterfactual experiment, we allow demand to adjust while holding the supply side fixed. The results are rather heterogeneous across cities. For example, in Beijing, compared with the actual changes after the HPR, the counterfactual price goes up more and the transaction volume goes down less. This exercise illustrates the role of supply-side adjustment after the HPR: firms could have set higher prices in response to the more inelastic demand if the supply side (i.e., marginal cost) did not change. However, in reality the decreased marginal cost after the HPR led to a lower price level than the counterfactual case. To see this, note that because holding cost becomes higher after the HPR, developers are willing to set a lower price to sell quickly. Another possible explanation is the following: Given that the central government is very concerned with housing price bubbles, and in response, some local governments directly impose implicit price 
ceilings as part of HPR. ${ }^{22}$ Regarding the welfare results, we can see that the consumer surplus change is less negative and that the total profit change is lower than in the actual case. These results for Shanghai, Hangzhou, and Wuhan are similar to those for Beijing. However, as expected (given the estimation results), Guangzhou's results are quite different: price decreases (quantity is slightly smaller) and welfare improves in comparison to the actual case.

The second set of counterfactual results show that the counterfactual prices are lower than the actual ones in all cities except Guangzhou. The counterfactual sales are higher in Guangzhou, Hangzhou, and Wuhan but lower in Beijing and Shanghai. Note that the decrease in price does not necessarily lead to increased quantity, because the overall market size shrinks. Regarding the welfare results, except for in Guangzhou, buyers are better off than in the actual case mainly because of the decreased price; however, the social welfare changes, which account for both buyers' and developers' interests, are ambiguous and different across cities.

The third counterfactual exercise mimics the lottery scheme as the allocation rule, where we keep the demand parameters fixed but allow market size to shrink. The supply side (marginal cost) also adjusts to reflect the changes in the financial holding cost. Under the random lottery, price changes are virtually the same as in the second counterfactual simulation; however, the quantity of sales are much lower (except in Hangzhou) because of the decreased market size. In general, the lottery scheme benefits overall consumer surplus but tends to reduce developer profits. Again, the overall changes in social welfare vary across cities, which highlights the importance of tailoring specific housing policy design to each city.

In this counterfactual design, we implicitly assume that the changes in estimated demand are exclusively due to the composition change in the population of buyers (the first interpretation of changes in price elasticities due to the HPR in Subsection 6.1). Put differently, even though the lottery scheme does not change the composition of buyers (in terms of demographics), buyers' preferences can still change. If this is the case, then our simulation may underestimate the price increase and thus overstate the welfare benefits to consumers. Hence, we should keep this mind when interpreting the simulation results.

\footnotetext{
${ }^{22}$ Homes sold above the price ceiling sometimes take longer or encounter difficulties in completing transactions online, according to anecdotal evidence.
} 


\section{Table 9}

Baseline Counterfactual Results: Changes in Price, Quantity and Welfare One Year Before and After HPR

\begin{tabular}{llllcccc}
\hline & & Ave. & Ave. & Total & Consumer & Developer & Social \\
& & Price & Quantity & Quantity & Surplus & Profit & Welfare \\
\hline Beijing & Actual & 0.169 & -26.355 & $-42,528$ & $-159,387$ & 197,759 & 38,372 \\
& Counterfactual I & 0.453 & -8.146 & $-24,331$ & $-17,317$ & $-47,712$ & $-65,029$ \\
& Counterfactual II & -0.367 & -28.784 & $-85,976$ & 47,772 & $-193,817$ & $-146,045$ \\
& Counterfactual III & -0.367 & -31.946 & $-95,423$ & 27,039 & $-200,886$ & $-173,847$ \\
\hline Shanghai & Actual & 0.328 & -4.482 & $-13,330$ & $-84,369$ & $1,415,387$ & $1,331,018$ \\
& Counterfactual I & 4.234 & -8.001 & $-45,885$ & $-23,937$ & $-470,798$ & $-494,735$ \\
& Counterfactual II & -0.041 & -22.673 & $-130,027$ & 613 & $-1,346,176$ & $-1,345,563$ \\
& Counterfactual III & -0.041 & -23.385 & $-134,114$ & 455 & $-1,384,874$ & $-1,384,419$ \\
\hline Guangzhou & Actual & 0.259 & 6.068 & 11,541 & $-120,502$ & 3,021 & $-117,481$ \\
& Counterfactual I & -0.239 & 3.235 & 7,179 & 35,129 & 1,021 & 36,149 \\
& Counterfactual II & 0.019 & 6.425 & 14,258 & $-3,904$ & 5,107 & 1,204 \\
& Counterfactual III & 0.019 & -4.392 & $-9,746$ & $-2,936$ & 905 & $-2,031$ \\
\hline Hangzhou & Actual & 0.081 & -17.589 & 7,402 & 171,906 & 13,427 & 185,333 \\
& Counterfactual I & 0.080 & -4.978 & $-8,204$ & $-3,502$ & $-2,855$ & $-6,358$ \\
& Counterfactual II & -0.130 & 71.92 & 118,520 & 84,218 & 7,428 & 91,646 \\
& Counterfactual III & -0.129 & -4.543 & $-7,487$ & 8,289 & $-8,410$ & -120 \\
\hline Wuhan & Actual & 0.118 & -22.715 & 1,064 & $-1,710,640$ & 115,273 & $-1,595,508$ \\
& Counterfactual I & 0.120 & -3.935 & $-18,948$ & $-23,544$ & $-11,949$ & $-35,472$ \\
& Counterfactual II & -0.201 & -5.367 & $-25,851$ & 82,953 & $-95,130$ & $-12,248$ \\
& Counterfactual III & -0.201 & -20.990 & $-101,109$ & 52,758 & $-111,415$ & $-58,702$ \\
\hline
\end{tabular}

Notes: (a) All numbers refer to the changes between 4-quarter average before HPR and 4-quarter average after HPR, except for Beijing, which is based on 2 quarters before and after HPR due to data limitations. (b) All the price and welfare numbers (consumer surplus, firm profit, and social welfare) are in 10,000 CNY. (c) "Actual" refers to the changes in the transaction data. Counterfactual I adjusts demand and fixes supply. Counterfactual II adjusts supply and fixes demand. Counterfactual III mimics lottery scheme, fixes demand, and lets market size and supply change.

As a sanity check, we compare our model's general prediction about the lottery scheme with some high-level summary statistics from a couple of cities that do implement the lottery rule. After our sample period, some cities indeed carry out the lottery scheme. For new housing projects in which demand exceeds supply, the government initiates random draws to ensure less rent seeking. 
Among our sample cities, Shanghai implemented a lottery in May 2017, and Hangzhou implemented a lottery in April 2018. Table A1 in the Appendix shows the average monthly housing price for new home sales in 2017-18. We find that housing prices drop right after the lottery implementation in both Shanghai and Hangzhou. This is consistent with our counterfactual III results, where housing price also declines. The magnitude of the decline differs, as the actual lotteries in Shanghai and Hangzhou are only for projects with excess demand, and the counterfactual assumes lottery for all projects. In addition, counterfactual III assumes that the magnitude of market size change is the same as that of actual change, where in the actual lottery scheme this need not be the case.

Finally, we run these counterfactual simulations under the two alternative assumptions on firms' conduct. Table 10 shows the results for the case of a more competitive market (than the baseline case) described in Section 5.3 with $\gamma_{1}=0.5$. In this case, developers' (static) market power is weaker and depends less on the demand elasticity than the baseline case. So, as shown by the first counterfactual design, the equilibrium price/quantity adjustments due to demand change are smaller. Also, the second and third counterfactual results are similar to those for the baseline case but with smaller welfare loss in most cases. Overall, in a more competitive market environment, the compositional change in demand has less impact on the equilibrium outcome and causes less welfare loss for most cases.

Table 11 shows the results for the case in which all the firms form a monopoly and jointly maximize the total profit (i.e., full collusion), as described in Section 5.3 with $\gamma_{2}=1$. This is an extreme case without competition in which developers have maximum market power. As expected, compared with the baseline case, the price is higher and the quantity is lower for most cases, which leads to worsened consumer and social welfare. However, the results from this extreme case are rather close to the baseline case, so again our results seem not very sensitive to the supply-side assumption regarding firm conduct. 
Table 10

Counterfactual Results: More Competitive Market

\begin{tabular}{llcccccc}
\hline & & Ave. & Ave. & Total & Consumer & Developer & Social \\
& & Price & Quantity & Quantity & Surplus & Profit & Welfare \\
\hline Beijing & Counterfactual I & 0.062 & -1.665 & $-4,975$ & $-1,836$ & $-4,510$ & $-6,346$ \\
& Counterfactual II & -0.252 & 3.238 & 9,671 & 18,560 & $-57,303$ & $-38,742$ \\
& Counterfactual III & -0.252 & -13.549 & $-40,471$ & 10,644 & $-72,825$ & $-62,181$ \\
\hline Shanghai & Counterfactual I & 1.805 & -3.837 & $-22,007$ & $-16,351$ & $-112,900$ & $-129,251$ \\
& Counterfactual II & -0.187 & -17.619 & $-101,025$ & 2,884 & $-597,507$ & $-594,625$ \\
& Counterfactual III & -0.187 & -19.689 & $-112,898$ & 2,161 & $-637,153$ & $-634,993$ \\
\hline Guangzhou & Counterfactual I & -0.239 & 3.306 & 7,335 & 33,102 & 522 & 33,624 \\
& Counterfactual II & 0.012 & 14.248 & 31,616 & $-2,247$ & 5,387 & 3,140 \\
& Counterfactual III & 0.012 & 1.418 & 3,148 & $-1,704$ & 2,551 & 846 \\
\hline \multirow{2}{*}{ Hangzhou } & Counterfactual I & 0.031 & -2.101 & $-3,462$ & $-1,058$ & -602 & $-1,661$ \\
& Counterfactual II & -0.051 & 15.496 & 20,548 & 55,979 & -482 & 55,497 \\
& Counterfactual III & -0.051 & 4.309 & 6,791 & 12,887 & -148 & 12,739 \\
\hline Wuhan & Counterfactual I & -0.003 & 0.133 & 639 & 676 & 178 & 853 \\
& Counterfactual II & -0.104 & 14.797 & 71,275 & 38,057 & $-35,355$ & 2,664 \\
& Counterfactual III & -0.104 & -8.707 & $-41,942$ & 24,204 & $-45,067$ & $-20,887$ \\
\hline
\end{tabular}

Note: (a) All numbers refer to the changes between 4-quarter average before HPR and 4-quarter average after HPR, except for Beijing which is based on 2 quarters before and after HPR due to data limitations. (b) All the price and welfare numbers (consumer surplus, firm profit, and social welfare) are in 10,000 CNY. (c) "Actual" refers to the changes in the transaction data. Counterfactual I adjusts the demand and fixes the supply. Counterfactual II adjusts the supply and fixes the demand. Counterfactual III mimics the lottery scheme, fixes the demand, and lets market size and supply change. 


\section{Table 11}

Counterfactual Results: Joint Profit Maximization

\begin{tabular}{llllcccc}
\hline & & Ave. & Ave. & Total & Consumer & Developer & Social \\
& & Price & Quantity & Quantity & Surplus & Profit & Welfare \\
\hline \multirow{2}{*}{ Beijing } & Counterfactual I & 0.608 & -13.271 & $-39,640$ & $-10,976$ & $-104,492$ & $-115,468$ \\
& Counterfactual II & -0.253 & 2.557 & 7,638 & 18,490 & $-162,858$ & $-144,367$ \\
& Counterfactual III & -0.253 & -13.922 & $-41,585$ & 11,257 & $-209,702$ & $-198,445$ \\
\hline \multirow{2}{*}{ Shanghai } & Counterfactual I & 6.912 & -11.828 & $-67,833$ & $-16,863$ & $-1,098,838$ & $-1,115,701$ \\
& Counterfactual II & -0.008 & -18.393 & $-105,392$ & 0 & $-1,717,006$ & $-1,717,006$ \\
& Counterfactual III & -0.008 & -20.260 & $-116,091$ & 0 & $-1,887,694$ & $-1,887,694$ \\
\hline \multirow{2}{*}{ Guangzhou } & Counterfactual I & -0.218 & 3.006 & 6,669 & 29,628 & 1,777 & 31,405 \\
& Counterfactual II & 0.057 & 9.349 & 20,745 & $-8,675$ & 19,270 & 10,595 \\
& Counterfactual III & 0.057 & -2.216 & $-4,917$ & $-6,578$ & 8,887 & 2,309 \\
\hline \multirow{2}{*}{ Hangzhou } & Counterfactual I & 0.079 & -5.016 & $-8,266$ & $-2,509$ & $-4,266$ & $-6,775$ \\
& Counterfactual II & -0.136 & 19.73 & 25,532 & 180,785 & 583 & 181,368 \\
& Counterfactual III & -0.136 & -5.27 & $-8,692$ & 6,456 & $-10,811$ & $-4,355$ \\
\hline \multirow{2}{*}{ Wuhan } & Counterfactual I & 0.344 & -11.524 & $-55,486$ & $-53,566$ & $-56,720$ & $-110,231$ \\
& Counterfactual II & -0.192 & 21.023 & 101,269 & 85,028 & $-84,236$ & 707 \\
& Counterfactual III & -0.192 & -4.935 & $-23,774$ & 54,078 & $-138,073$ & $-84,050$ \\
\hline
\end{tabular}

Note: (a) All numbers refer to the changes between 4-quarter average before HPR and 4-quarter average after HPR, except for Beijing which is based on 2 quarters before and after HPR due to data limitations. (b) All the price and welfare numbers (consumer surplus, firm profit and social welfare) are in 10,000 CNY. (c) "Actual" refers to the changes in the transaction data. Counterfactual I adjusts the demand and fixes the supply. Counterfactual II adjusts the supply and fixes the demand. Counterfactual III mimics the lottery scheme, fixes the demand, and lets market size and supply change.

\subsection{Further Discussions}

In this subsection we compare our results with the existing literature. As most related studies focus on the effect of the HPR on percentage changes in price and quantity, we calculate the percentage changes in the actual and counterfactuals in Table A3 in the Appendix. Our comparison mainly focuses on the studies that use DID or regression discontinuity design (RDD) approach using transaction data.

Existing studies using DID or RDD have consensus that the HPR reduces transaction volume, while there is less agreement on the effect on prices. Some find small or insignificant reduction in prices; others find prices increased after the HPR. Somerville et al. (2020), using monthly projectlevel new home sales in four cities (Chengdu, Guangzhou, Hefei, and Qingdao) and a DID approach, find there is no significant effect on prices and that the size of point magnitude is very 
small. They find a large decline in sales volume: about $40 \%$ in the first six months following the HPR implementation and less than 30\% after 12 months. We provide estimates separately for each city, and we add a simple average over five-city's estimates in the last column of Table A3. Our average 12-month quantity change after the HPR ranges from $6.75 \%$ to $19.12 \%$, a smaller effect than Somerville et al. (2020).

Using transactions on resales in Guangzhou between January 2008 and December 2011, Jia et al. (2017) find that implementing the HPR increased prices by about $6 \%$. Our findings also show prices increased after HPR in Guangzhou, but with a larger magnitude (20\%) compared with their estimates. The main difference is that they use transactions on resales while we use project-level transaction data on new home sales. Also, they did not exclude the two administrative districts Zengcheng and Conghua, where the HPR was not implemented.

Sun et al. (2017) find a $17 \%$ to $24 \%$ decline in resale price and $50 \%$ to $75 \%$ reduction in transaction volume, using resale transaction data in Beijing. Our estimate on quantity is much smaller than theirs. We find the reduction in transaction volume ranges from $9.5 \%$ to $38 \%$. Again, the HPR could differ in its effect on new home market and resale market.

Besides the above literature using project-level or housing-unit-level transaction data, some studies use city-level panel data. For example, Cao et al. (2015) found that housing price on average declined by $18.3 \%$ and sales volume dropped by $60 \%$, four quarters after implementing HPR, using 70-city quarterly panel data on various real estate market indicators in 2008-13. ${ }^{23}$ Our results are based on several large cities and thus not directly comparable with this literature, and also indicates that heterogeneity across cities is fundamentally important and policy designs should be city specific.

The only reduced-form analysis that tries to distinguish demand side and supply side is Somerville et al. (2020). Their supply-side estimate is based on price bid of land rather than the price of new home. The point estimate of bid price reduction is between $2 \%$ and $11 \%$ but the effect is not statistically significant. Our counterfactual II suggests that holding consumers' behavior constant and allowing firms to adjust their behavior, the supply-side adjustments reduce price by $10.86 \%$ and reduce quantity by $15.16 \%$. The main difference is that our supply-side model focuses on the short-run pricing behavior while their study is more about the long-run land acquiring

\footnotetext{
${ }^{23}$ There are other studies that use such city level panel and publish in Chinese, so our comparison with the literature is not exhaustive.
} 
decisions. Hence, we think our results complement theirs in understanding the supply side of the Chinese new home market.

\section{Conclusion}

Housing accounts for a large portion of household assets; government intervention in the housing market could affect the economy in various ways. This paper examines the impact of a policy of home purchase restrictions (HPR) on China's housing market. The policy restricts the number of houses that a household can purchase based on its Hukou status and the number of years of continuous deposits into a social security account. It also strengthened regulations on the down payment ratio and mortgage interest rate. We analyze changes in consumer behavior and firms' responses after policy intervention by estimating a structural model of demand, supply, and market equilibrium. Using project-level sales data on China's newly constructed homes in five large cities - Beijing, Shanghai, Guangzhou, Hangzhou, and Wuhan-between 2008 and 2017, we find that for all the cities except Guangzhou, after HPR implementation, consumers become less price elastic and real estate developers have stronger incentives to sell quickly by lowering prices. This suggests that the HPR does partly meet its policy goal of reducing speculative housing purchases and stabilizing housing prices. Because of data availability, we only use three tier-1 cities and two tier-2 cities in our structural estimation, and we acknowledge that our conclusions might not hold for other parts of China, as housing price patterns could be different in smaller cities.

However, government intervention might also have unintended consequences for individual or firm behavior and could lead to welfare loss. Our counterfactual analyses suggest that implemented HPR leads to substantial consumer welfare loss by changing the structure of demand and developer response. Our counterfactual analyses also show that alternative housing market interventions that keep demand unchanged and only affect firms' strategies might be better in terms of social welfare; however, the conclusions also differ across cities, which emphasizes the importance of city-specific policies. 


\section{References}

Bajari, P., P. Chan, D. Krueger, and D. Miller (2013). A dynamic model of housing demand: Estimation and policy implications. International Economic Review 54(2), 409-442.

Baumol, William J. (1986). Contestable markets: an uprising in the theory of industry structure. Microtheory: Applications and Origins, 40-54.

Bayer, P., F. Ferreira, and R. McMillan (2007). A unified framework for measuring preferences for schools and neighborhoods. Journal of Political Economy 115(4), 588-638.

Berry, S. (1994). Estimating discrete-choice models of product differentiation. The RAND Journal of Economics, 242-262.

Berry, S. and P. Jia (2010). Tracing the woes: An empirical analysis of the airline industry. American Economic Journal: Microeconomics 2(3), 1-43.

Berry, S., J. Levinsohn, and A. Pakes (1995). Automobile prices in market equilibrium. Econometrica: Journal of the Econometric Society, 841-890.

Bresnahan, T., 1989. Empirical studies of industries with market power. In: Schmalansee R., Willig, R. (Eds.), The Handbook of Industrial Organization, vol. 2. Elsevier, Amsterdam.

Cai, H., J. V. Henderson, and Q. Zhang (2013). China's land market auctions: evidence of corruption?. The Rand journal of economics, 44(3), 488-521.

Ciliberto, Federico and Jonathan W. Williams (2014). Does multimarket contact facilitate tacit collusion? Inference on conduct parameters in the airline industry. The RAND Journal of Economics 45(4), 764-791

Deng, Y., J. Gyourko, and T. Li (2018). Singapore's cooling measures and its housing market. Journal of Housing Economics 45, 101573.

Deng, Y., J. Gyourko, and J. Wu (2012). Land and house price measurement in China. National Bureau of Economic Research Working Paper No. 18403.

$\mathrm{Du}, \mathrm{Z}$. and L. Zhang (2015). Home-purchase restriction, property tax and housing price in china: A counterfactual analysis. Journal of Econometrics 188(2), 558-568.

Gandhi, A. and J.-F. Houde (2019). Measuring substitution patterns in differentiated products industries. National Bureau of Economic Research Working Paper No. w26375.

Gandhi, A., Z. Lu and X. Shi (2019). Estimating demand for differentiated products with zeroes in market share data. Working Paper.

Genesove, D., and W. P. Mullin (1998). Testing static oligopoly models: conduct and cost in the 
sugar industry, 1890-1914. The RAND Journal of Economics, 355-377.

Jia, S., Y. Wang, and G.-Z. Fan (2018). Home-purchase limits and housing prices: Evidence from china. The Journal of Real Estate Finance and Economics 56(3), 386-409.

Murphy, A. (2018). A dynamic model of housing supply. American Economic Journal: Economic Policy, 243-267.

Nevo, Aviv (2001), Measuring market power in the ready-to-eat cereal industry. Econometrica 69(2), 307-342.

Patrick, B., M. Robert, M. Alvin, and T. Christopher (2016). A dynamic model of demand for houses and neighborhoods. Econometrica 84(3), 893-942.

Somerville, T., L. Wang, and Y. Yang. (2020), Using purchase restrictions to cool housing markets: A within-market analysis. Journal of Urban Economics, 115, 103189.

Sudhir, K. (2001), Competitive Pricing Behavior in the Auto Market: a Structural Analysis, Marketing Science.

Sun, W., S. Zheng, D. M. Geltner, and R. Wang (2017). The housing market effects of local home purchase restrictions: evidence from Beijing. The Journal of Real Estate Finance and Economics 55(3), 288-312.

Topel, R., and S. Rosen, S (1988). Housing investment in the United States. Journal of Political Economy 96(4), 718-740.

Wu, J., J. Gyourko, and Y. Deng (2012). Evaluating conditions in major Chinese housing markets. Regional Science and Urban Economics 42(3), 531-543. 


\section{Appendix}

\section{Table A1}

Average Housing Price in Shanghai and Hangzhou, Jan 2017-Sep 2018

\begin{tabular}{rrr}
\hline & Shangha & Hangzho \\
& i & $\mathrm{u}$ \\
\hline Jan-17 & 46,197 & 21,829 \\
Feb-17 & 46,513 & 18,389 \\
Mar-17 & 47,420 & 20,328 \\
Apr-17 & 47,110 & 21,080 \\
May-17 & $\mathbf{5 0 , 4 0 1}$ & 21,174 \\
Jun-17 & 49,179 & 21,625 \\
Jul-17 & 46,183 & 25,449 \\
Aug-17 & 48,978 & 26,643 \\
Sep-17 & 45,764 & 26,674 \\
Oct-17 & 48,191 & 28,147 \\
Nov-17 & 49,105 & 27,638 \\
Dec-17 & 49,317 & 25,066 \\
Jan-18 & 43,399 & 27,032 \\
Feb-18 & 42,544 & 27,528 \\
Mar-18 & 45,655 & 28,207 \\
Apr-18 & 46,960 & $\mathbf{2 8 , 7 1 7}$ \\
May-18 & 51,331 & 26,880 \\
Jun-18 & 50,839 & 28,512 \\
Jul-18 & 53,698 & 27,899 \\
Aug-18 & 55,918 & 27,586 \\
Sep-18 & 54,085 & 25,611 \\
\hline & &
\end{tabular}

Notes: (a) Data are obtained from Wind Economic Database. (b) This table shows average monthly price for new home sales in the cities of Shanghai and Hangzhou. (c) The numbers in bold indicate the timing of the lottery implementation: May 2017 for Shanghai and April 2018 for Hangzhou. 
Table A2: Demand Elasticities Explained by Demographics

\begin{tabular}{|c|c|c|c|}
\hline & \multicolumn{3}{|c|}{ Cross Elasticity } \\
\hline Age & $\begin{array}{c}\text { Own Elasticity } \\
3.480^{* * *} \\
(0.314)\end{array}$ & $\begin{array}{c}\text { Within Nest } \\
0.255^{* * *} \\
(0.0269)\end{array}$ & $\begin{array}{l}\text { Across Nest } \\
0.000116^{* * *} \\
(0.00000442)\end{array}$ \\
\hline Total family income & $\begin{array}{c}8.498 * * * \\
(0.786)\end{array}$ & $\begin{array}{c}0.647 * * * \\
(0.0683)\end{array}$ & $\begin{array}{c}0.000379 * * * \\
(0.0000115)\end{array}$ \\
\hline Family size & $\begin{array}{c}-100.1 * * * \\
(6.881)\end{array}$ & $\begin{array}{c}-6.887 * * * \\
(0.652)\end{array}$ & $\begin{array}{c}-0.00222 * * * \\
(0.000107)\end{array}$ \\
\hline Married & $\begin{array}{c}270.9 * * * \\
(18.23)\end{array}$ & $\begin{array}{c}22.81 * * * \\
(1.854)\end{array}$ & $\begin{array}{c}0.00161 * * * \\
(0.000308)\end{array}$ \\
\hline College or above & $\begin{array}{c}-63.43^{* * *} \\
(2.977)\end{array}$ & $\begin{array}{c}-2.075 * * * \\
(0.142)\end{array}$ & $\begin{array}{c}-0.000905 * * * \\
(0.0000218)\end{array}$ \\
\hline Constant & $\begin{array}{c}-160.4^{* * *} \\
(17.30) \\
\text { Yes }\end{array}$ & $\begin{array}{c}-15.99 * * * \\
(1.527) \\
\text { Yes }\end{array}$ & $\begin{array}{c}-0.00372 * * * \\
(0.000252) \\
\text { Yes }\end{array}$ \\
\hline City FE & Yes & Yes & Yes \\
\hline Year-quarter FE & 17406 & 17406 & 17406 \\
\hline No. of Obs & 0.538 & 0.239 & 0.907 \\
\hline R-squared & $3.480 * * *$ & $0.255^{* * *}$ & $0.000116^{* * *}$ \\
\hline
\end{tabular}


Table A3: Percentage Changes in Prices and Quantities, Actual and Counterfactuals

\begin{tabular}{|c|c|c|c|c|c|c|c|c|c|c|c|c|}
\hline & \multicolumn{2}{|c|}{ Beijing } & \multicolumn{2}{|c|}{ Shanghai } & \multicolumn{2}{|c|}{ Guangzhou } & \multicolumn{2}{|c|}{ Hangzhou } & \multicolumn{2}{|c|}{ Wuhan } & \multicolumn{2}{|c|}{ Five-city average } \\
\hline & $\begin{array}{l}\text { Avg } \\
\text { Price }\end{array}$ & $\begin{array}{c}\text { Avg } \\
\text { Quantity }\end{array}$ & $\begin{array}{l}\text { Avg } \\
\text { Price }\end{array}$ & $\begin{array}{c}\text { Avg } \\
\text { Quantity }\end{array}$ & $\begin{array}{l}\text { Avg } \\
\text { Price }\end{array}$ & $\begin{array}{c}\text { Avg } \\
\text { Quantity }\end{array}$ & $\begin{array}{l}\text { Avg } \\
\text { Price }\end{array}$ & $\begin{array}{c}\text { Avg } \\
\text { Quantity }\end{array}$ & $\begin{array}{l}\text { Avg } \\
\text { Price }\end{array}$ & $\begin{array}{c}\text { Avg } \\
\text { Quantity }\end{array}$ & $\begin{array}{l}\text { Avg } \\
\text { Price }\end{array}$ & $\begin{array}{c}\text { Avg } \\
\text { Quantity }\end{array}$ \\
\hline Actual & 10.07 & -26.68 & 14.55 & -8.11 & 20.23 & 9.66 & 4.16 & -28.16 & 17.78 & -22.20 & 13.35 & -15.10 \\
\hline Counterfactual I & 25.70 & -9.50 & 175.10 & -15.09 & -16.90 & 4.90 & 3.97 & -9.67 & $\begin{array}{c}16.46 \\
-\end{array}$ & -4.39 & 40.87 & -6.75 \\
\hline Counterfactual II & -20.80 & -38.17 & -1.72 & -45.08 & 1.32 & -9.52 & -5.72 & 38.88 & $\begin{array}{c}27.40 \\
-\end{array}$ & -21.91 & -10.86 & -15.16 \\
\hline Counterfactual III & -20.80 & -37.25 & -1.71 & -44.11 & 1.32 & -6.66 & -5.69 & 15.85 & 27.50 & -23.44 & -10.88 & -19.12 \\
\hline
\end{tabular}

Notes: (a) Authors' calculations of percentage changes in average prices and quantities one year before and after HPR was

implemented. (b) All numbers are in \%. (c) The last two columns report simple averages of the estimates in each city. 
Figure A1

Trends in Housing Prices and Transactions in Shanghai

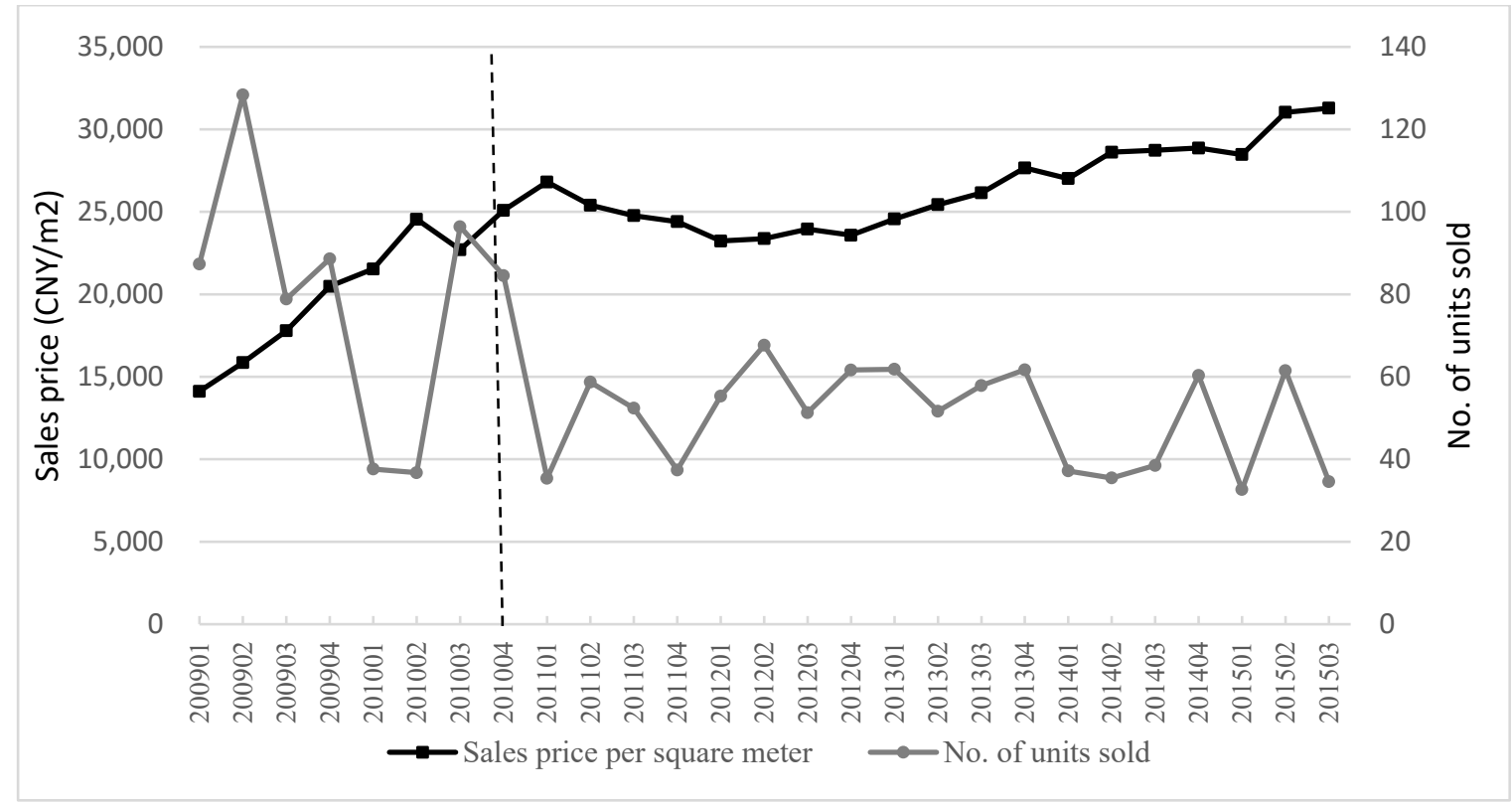

Figure A2

Trends in Housing Prices and Transactions in Guangzhou

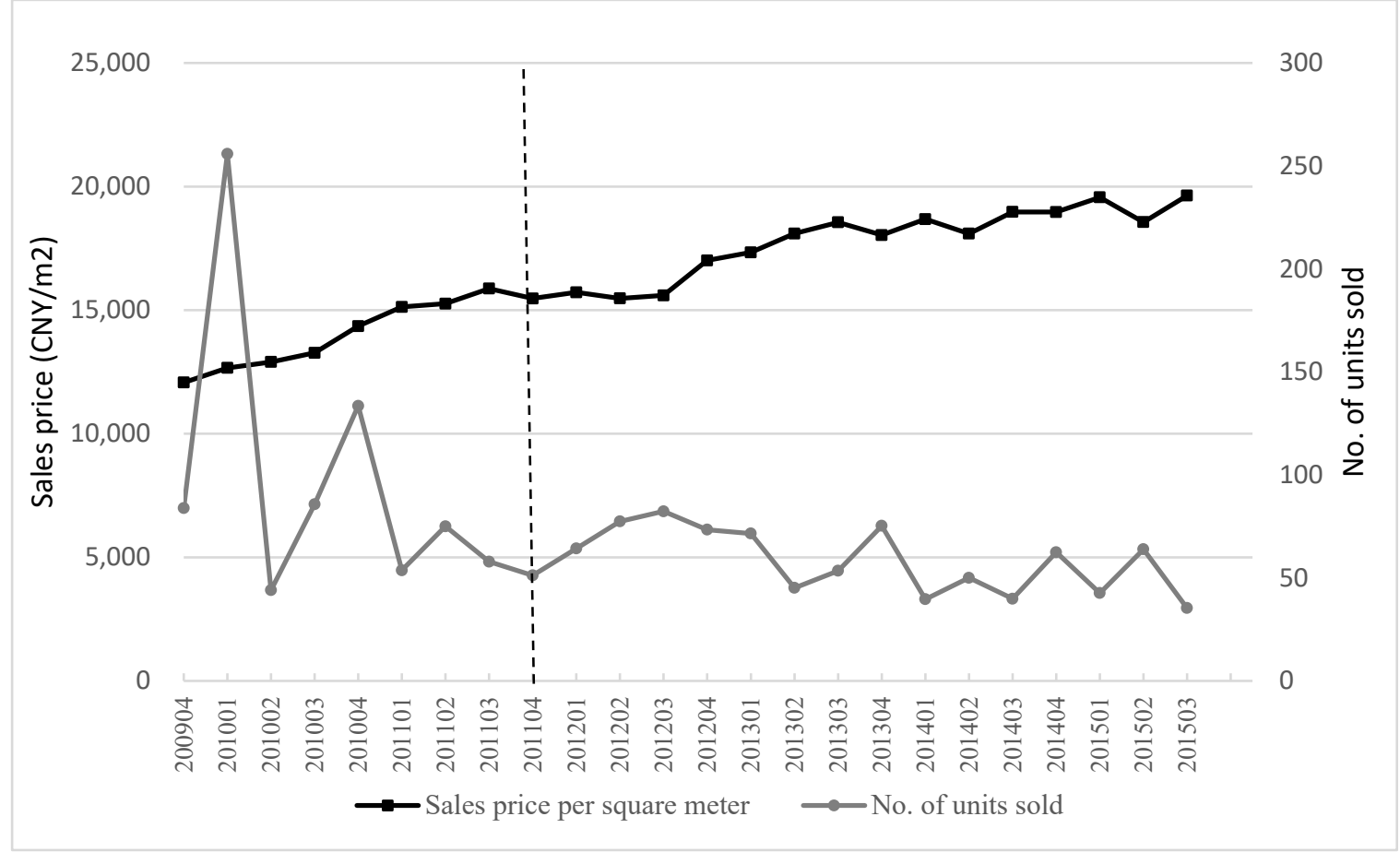


Figure A3

Trends in Housing Prices and Transactions in Hangzhou

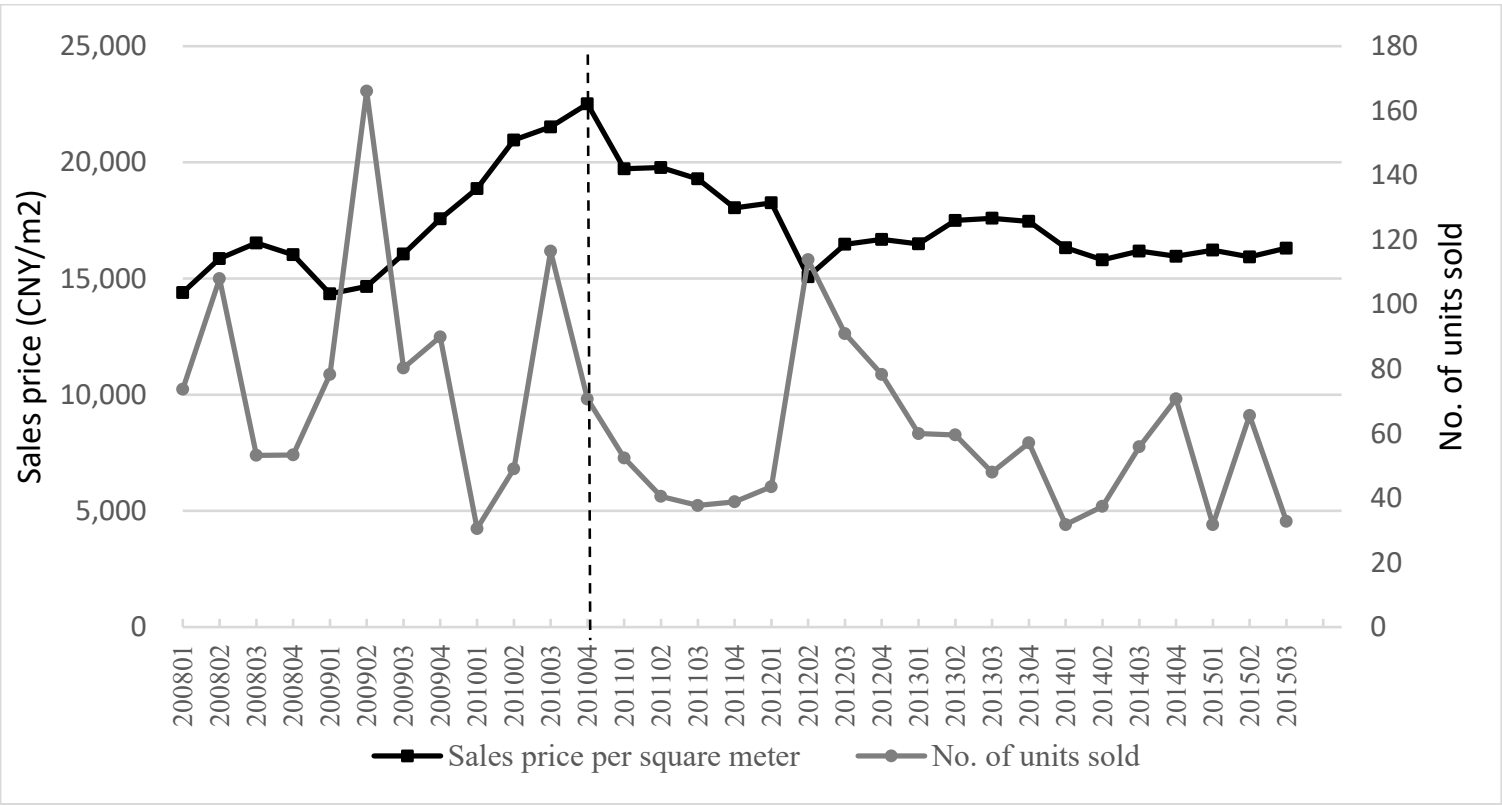

\section{Figure A4}

Trends in Housing Prices and Transactions in Wuhan

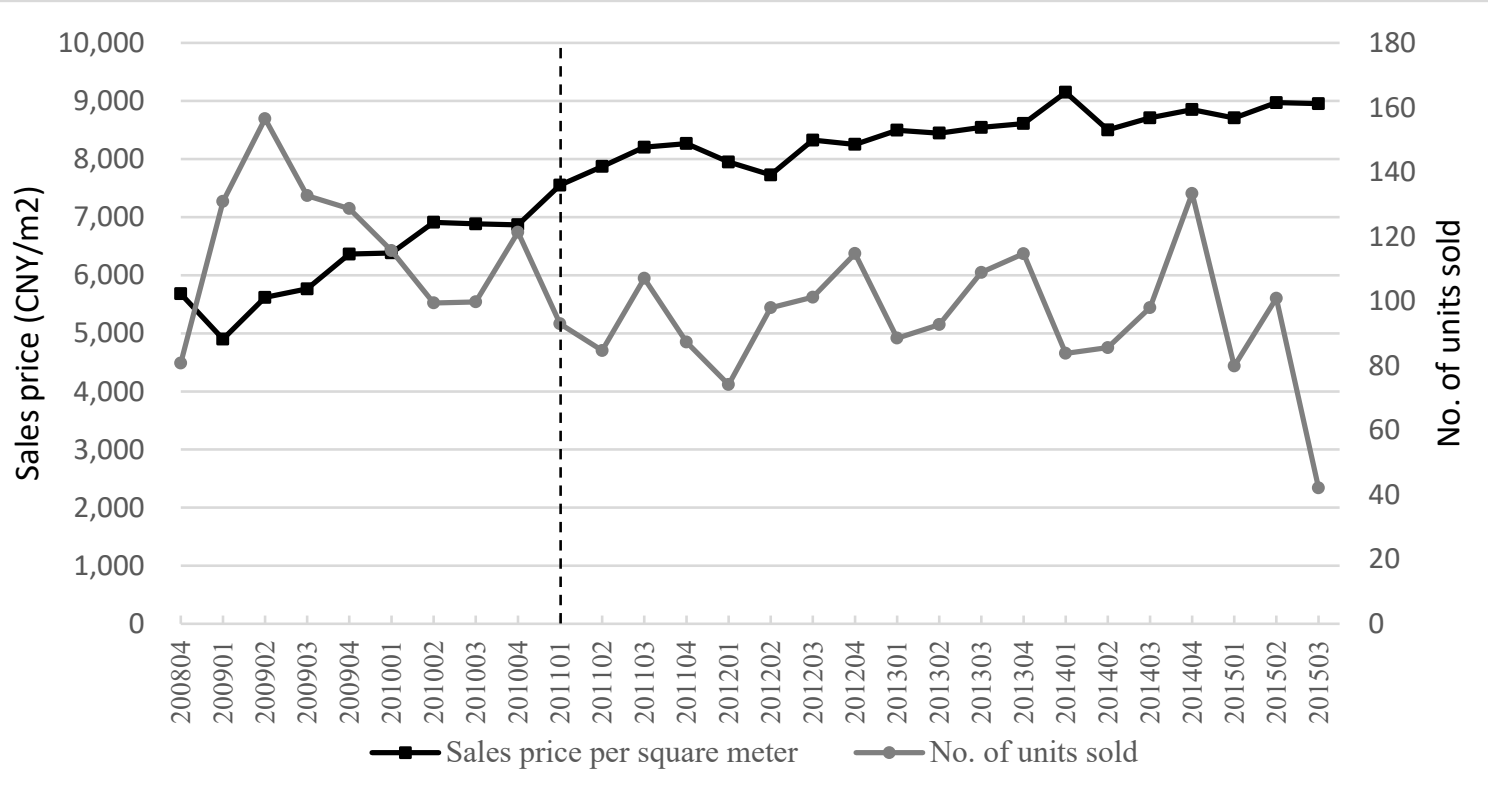




\section{Figure A5}

Model Fit: Prediction vs Actual Transaction Volume
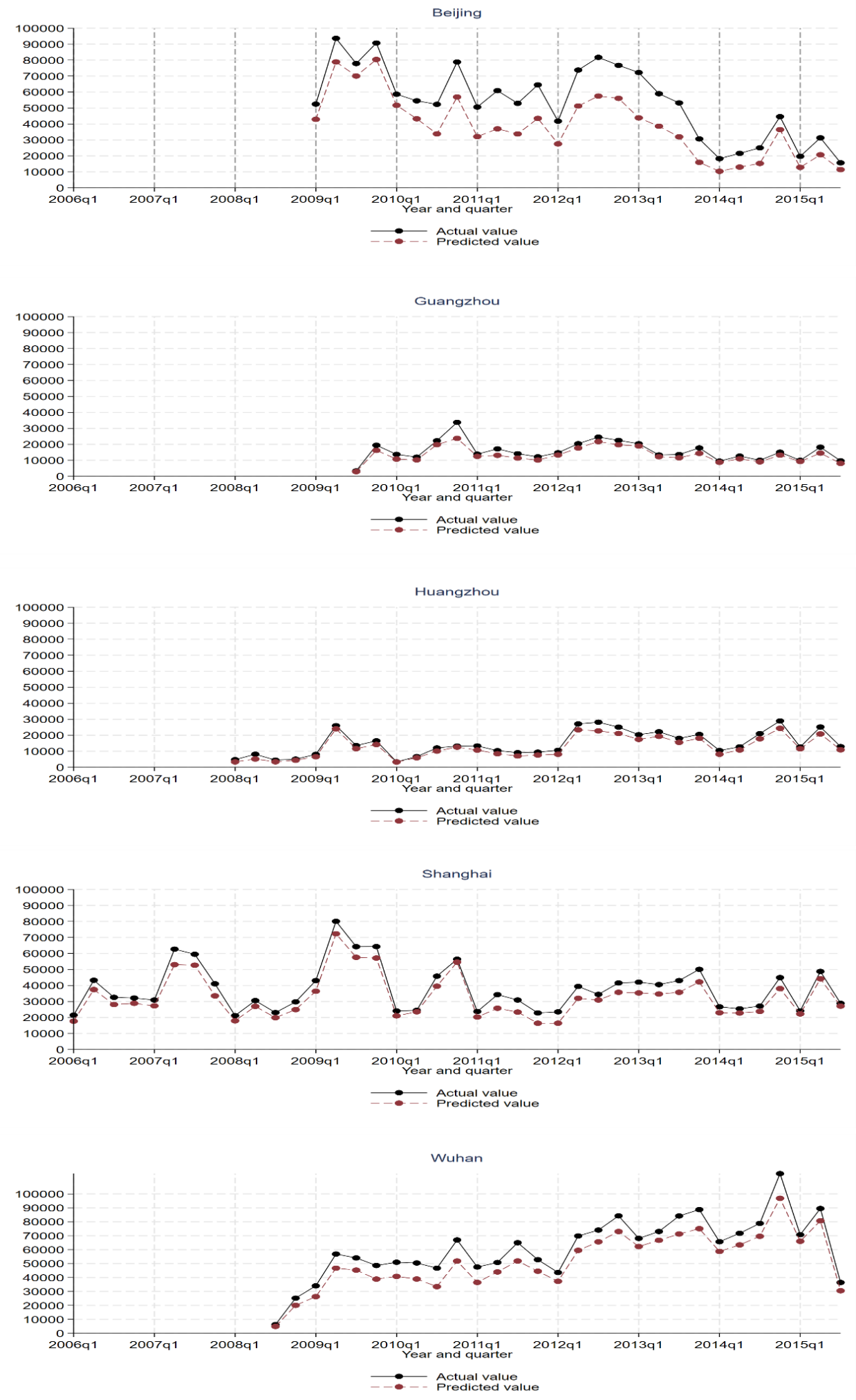